\title{
Shh establishes an Nkx3.2/Sox9 autoregulatory loop that is maintained by BMP signals to induce somitic chondrogenesis
}

\author{
Li Zeng, Hervé Kempf,, ${ }^{1}$ L. Charles Murtaugh, ${ }^{1}$ Mie Elissa Sato, ${ }^{1}$ and Andrew B. Lassar ${ }^{2}$ \\ Department of Biological Chemistry and Molecular Pharmacology, Harvard Medical School, Boston, Massachusetts 02115, USA
}

\begin{abstract}
Prior work has established that transient Shh signals from the notochord and floor plate confer a competence in somitic tissue for subsequent BMP signals to induce chondrogenesis. We have therefore proposed that Shh induces a factor(s) that renders somitic cells competent to chondrify in response to subsequent BMP signals. Recently, we have shown that forced expression of Nkx3.2, a transcriptional repressor induced by Shh, is able to confer chondrogenic competence in somites. In this work, we show that administration of Shh or forced Nkx3.2 expression induces the expression of the transcription factor Sox9 in the somitic tissue. Forced expression of Sox9 can, in turn, induce robust chondrogenesis in somitic mesoderm, provided that BMP signals are present. We have found that in the presence of BMP signals, Sox9 and Nkx3.2 induce each other's expression. Thus, Nkx3.2 may promote axial chondrogenesis by derepressing the expression of Sox9 in somitic mesoderm. Furthermore, forced expression of either Sox9 or Nkx3.2 not only activates expression of cartilage-specific genes in somitic mesoderm, but also promotes the proliferation and survival of the induced chondrocytes in the presence of BMP signals. However, unlike Nkx3.2, Sox9 is able to induce de novo cartilage formation in non-cartilage-forming tissues. Our findings suggest that Shh and BMP signals work in sequence to establish a positive regulatory loop between Sox9 and Nkx3.2, and that Sox9 can subsequently initiate the chondrocyte differentiation program in a variety of cellular environments.
\end{abstract}

[Key Words: Sox9; Nkx3.2; Shh; BMP; somite; chondrogenesis]

Received November 2, 2001; revised version accepted June 4, 2002.

Paraxial mesoderm in vertebrate embryos is separated into transient clusters of cells termed somites. Somites are initially epithelial spheres of cells, which undergo a maturation process to give rise to three distinct cell types. Cells located in the dorsal domain of the somite become the dermomyotome, a progenitor tissue that gives rise to skeletal muscle and dermis. Cells located in the ventral domain of the somite deepithelialize to form the sclerotome, a progenitor tissue that gives rise to the cartilage template of the vertebrae and ribs (Hirsinger et al. 2000; Stockdale et al. 2000). The determination of these various somitic cell fates is induced by signals from the surrounding tissues. Wnt signals from the neural tube and ectoderm induce the formation of the dermomyotome. Wnt-1 and Wnt-3a, which are expressed in the neural tube, work in collaboration with Shh signals from the notochord and floor plate to induce the forma-

\footnotetext{
${ }^{1}$ These authors contributed equally to this work.

${ }^{2}$ Corresponding author.

E-MAIL andrew_lassar@hms.harvard.edu; FAX (617) 738-0516.

Article and publication are at http://www.genesdev.org/cgi/doi/10.1101/ gad.1008002.
}

tion of the medial myotome (Munsterberg et al. 1995; Arnold and Braun 2000; Borycki and Emerson 2000). On the other hand, signals from the notochord and floor plate are critical for the development of the sclerotome (Dockter 2000). Mouse mutants lacking the notochord never initiate sclerotome formation, as evidenced by the lack of the sclerotome marker Paxl (Dietrich et al. 1993), and mouse somite explants fail to express Paxl unless they are cocultured with either notochord or floor plate (Fan and Tessier-Lavigne 1994). Grafting an ectopic notochord or floor plate near the presomitic mesoderm region or between the neural tube and the somite expands the sclerotome (Brand-Saberi et al. 1993; Pourquie et al. 1993), leading to a conversion of the entire medial somite into cartilage (Pourquie et al. 1993). Furthermore, embryonic manipulations of chick embryos have shown that signals from the notochord and floor plate are necessary to maintain the survival of sclerotomal cells (Teillet et al. 1998). Thus, a signal (or signals) from the notochord is required to both induce and maintain the sclerotomal cell fate.

Numerous genetic studies have indicated that Sonic hedgehog (Shh), a secreted molecule expressed in the no- 
tochord and the floor plate, is responsible for the effects of these axial tissues on both sclerotome induction and survival. Infection of paraxial mesoderm with a Shhexpressing retrovirus expanded the domain of the sclerotome marker Paxl (Johnson et al. 1994) and was sufficient to induce the expression of this gene in cultured somites (Fan and Tessier-Lavigne 1994; Munsterberg et al. 1995). In addition, Shh-producing cells were able to restore Pax1 expression and vertebrae and rib formation in embryos whose notochords and neural tubes had been ablated, suggesting that Shh is sufficient to promote sclerotome formation (Teillet et al. 1998; Britto et al. 2000). In the Shh null embryo, sclerotome forms initially, but soon degenerates, resulting in the absence of the entire vertebral column, with severe defects of the rib structures (Chiang et al. 1996). These findings indicate that Shh is crucial for proper development of the sclerotome, and hence axial cartilage formation.

Bone morphogenetic proteins (BMPs) have also been shown to regulate cartilage formation as well. Whereas several studies have shown that BMP signals can block sclerotomal gene expression by inducing presumptive paraxial mesoderm cells to adopt a lateral plate fate (Tonegawa et al. 1997; Reshef et al. 1998), other studies have shown that BMP signals are necessary and sufficient for cartilage differentiation (Kawakami et al. 1996; Zou et al. 1997). These seemingly paradoxical opposite effects of BMP signaling on sclerotome formation were resolved by the use of an in vitro somite explant system that recapitulated the in vivo development of sclerotome (Murtaugh et al. 1999). It was found that administration of BMP4 to presomitic mesoderm (psm) cultures induced lateral plate gene expression and inhibited the expression of cartilage markers unless these cells were first exposed to Shh. Indeed, only a transient exposure to Shh was sufficient to induce a chondrogenic response of psm cells to subsequent BMP signals. Thus, Shh was proposed to confer a competence on presomitic cells to undergo BMP-dependent chondrogenesis (Murtaugh et al. 1999).

Based on this model, it was suggested that Shh induces the expression of a competence factor(s) that cooperates with BMP to promote cartilage differentiation (Murtaugh et al. 1999). One of the genes induced by Shh signals in paraxial mesoderm encodes the transcription factor Nkx3.2, the vertebrate homolog of Drosophila Bagpipe. Interestingly, Nkx3.2 is expressed in all cartilaginous tissues (Tribioli et al. 1997; Tribioli and Lufkin 1999), and its expression in somites can be maintained by BMP signals following a transient exposure to Shh (Murtaugh et al. 2001). Recently, we have shown that infection of presomitic mesoderm with a retrovirus encoding Nkx3.2 was able to confer a chondrogenic response to BMP signals in the absence of prior Shh administration (Murtaugh et al. 2001). Surprisingly, Nkx3.2 functions as a transcriptional repressor to induce somitic chondrogenesis, suggesting that it inhibits the expression of an inhibitor of this process (Murtaugh et al. 2001).

Several observations suggest that Shh signals induce other prochondrogenic differentiation factors in somites in addition to Nkx3.2. Firstly, although Nkx3.2 is expressed prior to the chondrocyte differentiation marker collagen IX in vertebrae precursor cells, Nkx3.2 expression does not precede that of collagen IX in rib progenitors (Murtaugh et al. 2001). Secondly, consistent with the relatively late expression of $\mathrm{Nkx} 3.2$ in ribs, mice embryos lacking their Nkx3.2 homolog, Bapx, develop normal ribs, although there are severe defects in vertebrae formation (Tribioli and Lufkin 1999). Thirdly, we have observed that BMP administration to presomitic mesoderm can occasionally induce low-level expression of the cartilage markers aggrecan and epiphycan, even in the absence of detectable Nkx3.2 expression. Finally, we have found that the kinetics of chondrogenic differentiation of somites infected with retroviral Nkx3.2 is slower than that in somites exposed to Shh, suggesting that Shh induces other prochondrogenic factors in addition to Nkx3.2 in sclerotomal progenitors (Murtaugh et al. 2001).

Another transcription factor that is expressed in all cartilaginous tissues is Sox9 ( $\mathrm{Ng}$ et al. 1997). Cells lacking Sox9 were unable to enter the cartilage differentiation program in chimeric mice embryos made up of wild-type and Sox9-deficient cells (Bi et al. 1999). Conversely, forced expression of Sox9 in the hindbrain and the branchial arches induced ectopic collagen II expression in these tissues (Bell et al. 1997). Furthermore, Sox 9 has been shown to bind to the promoters of the chondrocyte differentiation markers, collagen IIa and aggrecan, and activate their transcription (Lefebvre et al. 1997; Ng et al. 1997; Sekiya et al. 2000). Because these prior studies have indicated that Sox9 is an important chondrocyte differentiation factor, we evaluated the role of Sox9 in Shh-mediated somitic chondrogenesis. Here we show that the expression of Sox9 is regulated by both Shh and BMPs, and that forced expression of Sox9 is able to confer a chondrogenic response to subsequent BMP signals in the absence of any hedgehog signals. Moreover, Nkx3.2 and Sox9 promote each other's expression in a positive regulatory loop to achieve robust cartilage formation. Our findings suggest that Nkx3.2 confers competence for chondrogenic differentiation by derepressing the expression of Sox9 in response to BMP signals. Furthermore, Sox 9 and Nkx3.2 promote cell proliferation and survival in the presence of BMP signals. Whereas ectopic Sox9 can induce chondrogenesis in both paraxial mesoderm and lateral plate tissue, ectopic Nkx3.2 can only induce this differentiation program in paraxial mesoderm, indicating that Sox9 is the more potent chondrogenic differentiation factor.

\section{Results}

The expression of Sox 9 is regulated by sequential Shh and BMP signals

Our prior work has indicated that only a transient twoday exposure to Shh is sufficient to confer competence for subsequent BMP signals to induce chondrogenesis in 
cultured somites (Murtaugh et al. 1999). Thus, it seems likely that Shh initiates the expression of prochondrogenic transcription factors whose later expression is maintained by autoactivation, subsequent BMP signals, or both. We used the chick somite explant system to examine if somitic expression of Sox9 is regulated by Shh and BMP signals. Presomitic mesoderm (psm) from stage 10 chick embryos was explanted and cultured in either the absence or presence of Shh. After culturing for 1,2 , or $5 \mathrm{~d}$, explants were harvested and analyzed for gene expression by RT-PCR analysis. Because various experimental regimens had a large effect on somitic cell proliferation and survival (discussed below), we normalized all PCR analyses to an arbitrary level of GAPDH in each experiment. Treatment of psm with Shh induced the expression of Sox 9 and Nkx3.2 to maximal levels after only $1 \mathrm{~d}$ of culture (Fig. 1A, lane 2). Although $\mathrm{Nkx} 3.2$ expression is undetectable in somites cultured in the absence of Shh, a trace level of Sox9 is frequently present in such cultures (Fig. 1A, lanes 1,5). In contrast to Sox9 and Nkx3.2, the cartilage differentiation marker aggrecan was not induced during the first $2 \mathrm{~d}$ of Shh treatment (Fig. 1A, lanes 2,4), but was detectable following $5 \mathrm{~d}$ of Shh administration (Fig. 1A, lane 6). Thus, both Sox 9 and Nkx3.2 are induced by Shh, prior to the expression of cartilage differentiation markers.

We have established previously that chondrogenesis in psm cultures requires only a transient Shh signal followed by maintained BMP signals (Murtaugh et al. 1999). To evaluate whether the expression of Sox 9 in psm ex- plants was similarly maintained by BMP signals following transient exposure to Shh, we cultured psm with Shh and BMP2 for varying periods of time and harvested the explants after $5 \mathrm{~d}$ of culture. Because BMP2 and BMP4 show similar abilities to induce somitic chondrogenesis (Murtaugh et al. 1999), we used either protein in subsequent experiments. Continuous exposure of psm cultures to Shh for $5 \mathrm{~d}$ induced the expression of Sox 9 and Nkx3.2 (Fig. 1B, cf. lanes 1 and 2), but expression of these genes was not significantly increased following $5 \mathrm{~d}$ of culture after only transient exposure to Shh for $2 \mathrm{~d}$ (Fig. 1B, cf. lanes 1 and 4). However, if BMP2 was added to the cultures following the withdrawal of Shh at day 2, the expression of both Sox 9 and Nkx3.2 was maintained and the cultures showed robust levels of the cartilage differentiation markers aggrecan, epiphycan, and collagen IX (Fig. 1B, lane 6). We speculate that continual Shh treatment failed to yield high-level expression of these cartilage differentiation markers (Fig. 1B, lane 2) because endogenous BMPs are limiting under these culture conditions. Thus, although exposure of psm to BMP signals alone (either throughout the culture period, or for only the last $3 \mathrm{~d}$ of culture) failed to induce significant expression of either Sox9 or other chondrogenic markers (Fig. $1 \mathrm{~B}$, lanes 3,5$)$, BMP signals are able to maintain the expression of these genes following a transient exposure to Shh (Fig. 1B, lane 6).

Although these results indicate that BMP signals can maintain Sox9 expression following prior Shh treatment, they did not address whether the induction of Sox9 ex-
Figure 1. Sox9 expression is induced by Shh and maintained by BMP. (A) Shh induces Sox9 expression in presomitic mesoderm cultures. Explants of presomitic mesoderm were cultured in either the absence (lanes 1,3,5) or presence (lanes $2,4,6)$ of $\mathrm{Shh}(500 \mathrm{ng} / \mathrm{mL})$ for 1,2 , or $5 \mathrm{~d}$, after which they were harvested and processed for RNA analysis. RT-PCR was used to assay the expression of GAPDH (loading control), Sox9, Nkx3.2, and aggrecan. (B) BMP can maintain the expression of Sox9 after the withdrawal of Shh. Presomitic mesoderm explants were cultured in either control medium for $5 \mathrm{~d}$ (lane 1), or in medium containing Shh for $5 \mathrm{~d}$ (lane 2), BMP2 for $5 \mathrm{~d}$ (lane 3), Shh for $2 \mathrm{~d}$ followed by control medium for $3 \mathrm{~d}$ (lane 4), control medium for $2 \mathrm{~d}$ followed by BMP2 (100 ng/mL) for $3 \mathrm{~d}$ (lane 5), or Shh for $2 \mathrm{~d}$ followed by BMP2 for $3 \mathrm{~d}$ (lane 6). After $5 \mathrm{~d}$ of culture, the explants were harvested and processed for RT-PCR analysis. (C) Shh is able to maintain the expression of Sox9 in the absence of BMP signals. Presomitic mesoderm explants were cultured in the presence of Shh and 1\% FBS in the presence of either medium conditioned by control CHO cells (lane 1) or by Noggin-expressing CHO cells (lane 2). After $4 \mathrm{~d}$ of culture, the explants were harvested and processed for RTPCR analysis.

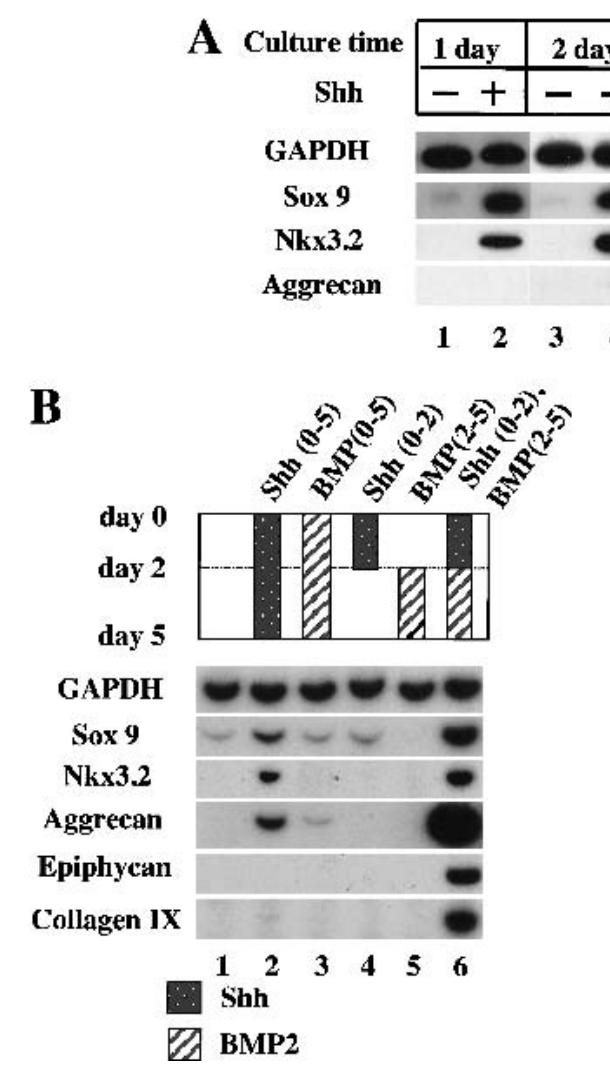


Nkx3.2/Sox9 loop promotes somitic chondrogenesis

pression by sustained Shh is similarly dependent on BMP signals. To address this issue we included serum (FBS) in the culture medium, which enhances Shh-induced chondrogenesis in the absence of exogenous BMP (Murtaugh et al. 1999). Under these conditions, the addition of the BMP antagonist Noggin depressed aggrecan expression and nearly abolished that of epiphycan and collagen IX (Fig. 1C, cf. lanes 1 and 2). In contrast, Noggin administration to cultures maintained in Shh failed to decrease the expression of either Sox9 or Nkx3.2 (Fig. 1C, cf. lanes 1 and 2). Thus, Shh is able to maintain Sox9 expression in cultured psm in the absence of BMP signals and is consistent with the fact that Shh induced the expression of Sox9 after only $1 \mathrm{~d}$ of culture (Fig. 1A, lane 2), prior to the expression of endogenous BMPs at day 3 (Murtaugh et al. 1999).

In summary, both Shh and BMP signals regulate the expression of Sox9 in paraxial mesoderm. Shh signaling is required initially to induce the expression of this gene in presomitic mesoderm, whereas subsequent BMP signals are able to maintain Sox9 expression even in the absence of Shh. This dependency on sequential inductive signals reflects the situation in the embryo, where dorsally migrating sclerotomal cells continue to express Sox9 after they have moved away from Shh sources (i.e., the notochord and floor plate) and moved into the vicinity of BMP sources (i.e., the dorsal neural tube; Marcelle et al. 1999).

\section{Ectopic expression of Sox9 promotes robust somitic chondrogenesis}

Because Sox 9 is expressed before the onset of cartilage differentiation markers, and is known to regulate the expression of collagen IIa and aggrecan (Lefebvre et al. 1997; Ng et al. 1997), we examined if forced expression of Sox9 would lead to activation of chondrocyte differentiation markers in somitic tissues. Presomitic mesoderm or somites I-III were explanted and infected with avian retroviruses (RCAS) encoding either GFP or Sox9. After $2 \mathrm{~d}$ of culture, BMP2 was added, and the explants were cultured for an additional 3 d. For comparison, we also infected the explants with an RCAS virus encoding Nkx3.2. RT-PCR analysis of viral transcripts indicated that the explants were readily infected by viruses encoding either Sox9 or Nkx3.2 (Fig. 2A, lanes 2,4 for Sox9 infection; lanes 6,8 for Nkx3.2 infection). Forced expression of Sox 9 induced robust expression of the cartilage markers aggrecan, epiphycan, and collagen IX (Fig. 2A, lanes 2,4). The expression levels of these markers are comparable to those induced by Shh followed by BMP2 administration (Fig. 2A, lane 9). Viral Nkx3.2 expression also led to activation of the cartilage genes aggrecan and epiphycan, and trace levels of collagen IX expression, as compared to that induced by either ectopic Sox9 or Shh administration (Fig. 2A, lanes 6,8; Murtaugh et al. 2001). However, continued culture of psm expressing viral Nkx3.2 for an additional day resulted in high-level collagen IX expression (Murtaugh et al. 2001; also see Fig. 4A, lane 8, below), suggesting that Nkx3.2
$\mathbf{\Lambda}$

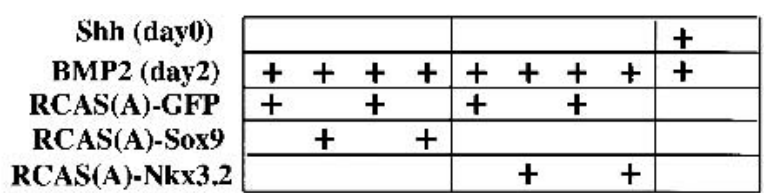

\section{GAPDII}

Aggrecan

Epiphycan

Collagen IX

Pax1

Gli-1

Patched

Ihh

Viral Sox9

Viral Nkx3.2

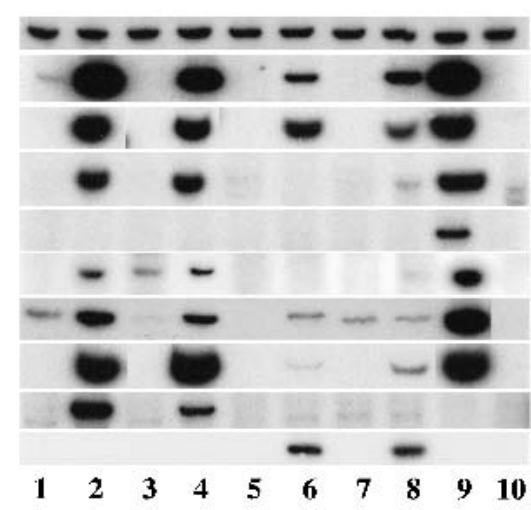

$\mathbf{B}$
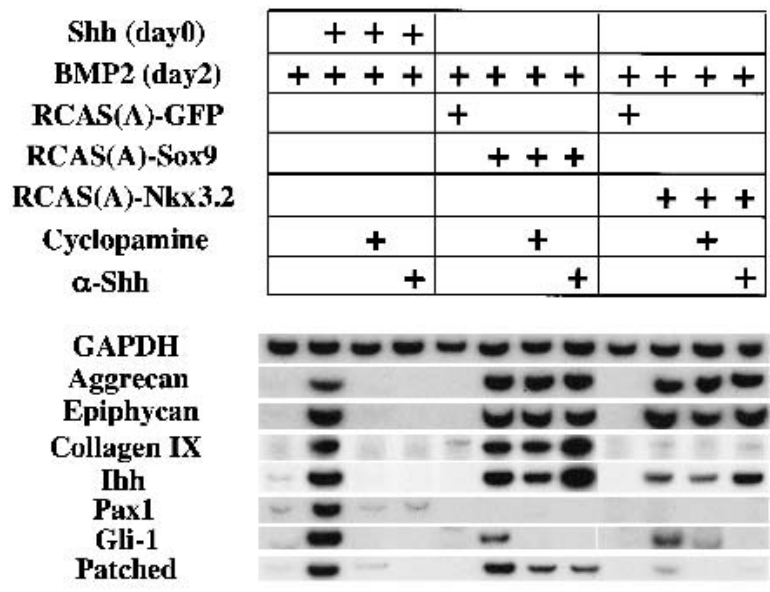

$\begin{array}{lllllllllllll}1 & 2 & 3 & 4 & 5 & 6 & 7 & 8 & 9 & 10 & 11 & 12\end{array}$

Figure 2. Sox 9 induces cartilage formation in the absence of Shh signaling. (A) Presomitic mesoderm or somites I-III were either infected with RCAS(A)-GFP (lanes 1,3,5,7), RCAS (A)Sox9 (lanes 2,4), or RCAS(A)-Nkx3.2 (lanes 6,8), or exposed to Shh (lane 9) or control medium (lane 10). Then, 2 d postinfection, BMP2 was added to the culture medium and the explants were cultured for an additional $3 \mathrm{~d}$. Gene expression was assayed by RT-PCR. (B) Hedgehog signaling antagonists block cartilage induction by Shh, but do not have any effect on Sox9 or Nkx3.2 induced chondrogenesis. Explants of somites I-III were either cultured in control medium (lanes 1,5,9) or in the presence of $500 \mathrm{ng} / \mathrm{mL}$ Shh (lanes 2-4), or infected with RCAS(A)Sox9 (lanes 6-8), RCAS(A)-Nkx3.2 (lanes 10-12), or RCAS(A)GFP (lanes 5,9). Explants were cultured in veratramine (which does not block hedgehog signaling at $500 \mathrm{nM}$; lanes 1,2,4-6,810,12 ), cyclopamine (which blocks hedgehog signaling at 500 $\mathrm{nM}$; lanes 3,7,11), or 5E1 (the anti-hedgehog antibody; lanes $4,8,12)$. Then, $2 \mathrm{~d}$ postinfection, BMP2 was added to the culture medium and the explants were cultured for an additional $3 \mathrm{~d}$. After $5 \mathrm{~d}$ of culture, the explants were harvested and gene expression was assayed by RT-PCR.

induces somitic chondrogenesis with slower kinetics than that following either Shh administration or ectopic Sox9 expression. 
To ascertain if chondrogenesis induced by Sox9 or Nkx3.2 is not simply caused by the activation of Shh signaling, we analyzed the expression of Shh target genes following infection of paraxial mesoderm with viruses encoding either Sox9 or Nkx3.2. Surprisingly, ectopic Sox9 induced the expression of the hedgehog-responsive genes Gli-1 and Patched, but ectopic Nkx3.2 did not appreciably do so (Fig. 2A, lanes 2,4,6,8). We speculated that the induction of Gli-1 and Patched in these cultures might be owing to the induced expression of Indian hedgehog (Ihh) in maturing chondrocytes (Marigo et al. 1996; Vortkamp et al. 1996; Iwasaki et al. 1997; Platt et al. 1997), which was highly expressed in RCAS-Sox9infected cultures (Fig. 2A, lanes 2,4), and only weakly expressed in RCAS-Nkx3.2-infected cultures (Fig. 2A, lanes 6,8). In contrast to Gli-1 and Patched, Paxl was only induced by Shh (Fig. 2A, lane 9), but neither by Sox9 (Fig. 2A, lanes 2,4) nor by Nkx3.2 (Fig. 2A, lanes 6,8). As Sox 9 and Nkx3.2 both induce the expression of Ihh in these cultures (Fig. 2A, lanes 2,4,6,8), it is unclear if the absence of Pax1 expression in these cultures reflects either different inductive properties of hedgehog family members, or the fact that somitic cells encounter endogenous Ihh signals at a time when their competence to express Paxl may have waned.

To further clarify if hedgehog signaling was necessary for either Sox9 or Nkx3.2 to induce chondrogenesis in somite cultures, we assayed whether these transcription factors could induce this differentiation program in cultures treated with reagents that block hedgehog signaling. Exposure of somites I-III to cyclopamine, which blocks hedgehog signal transduction (Cooper et al. 1998; Kim and Melton 1998; Incardona et al. 2000), or to 5E1, an antibody that is capable of blocking both Shh and Ihh signaling (Dyer et al. 2001), completely blocked the ability of sequential Shh/BMP signals to induce chondrogenesis in cultured somitic explants (Fig. 2B, lanes 3,4). Inclusion of veratramine, a molecule structurally related to cyclopamine that does not block hedgehog signaling at the concentration we are using (Incardona et al. 2000), failed to decrease chondrogenesis in Shh/BMP-treated cultures (Fig. 2B, lanes 1,2,4).

In contrast to Shh-treated cultures, neither cylopamine nor the anti-hedgehog blocking antibody 5E1 attenuated the ability of Sox9 or Nkx3.2 to induce chondrogenic differentiation (Fig. 2B, lanes 7,8,11,12). Whereas administration of hedgehog signal-blocking reagents failed to repress the ability of either Sox9 or Nkx3.2 to activate chondrocyte-specific gene expression, induction of both Gli-1 and Patched was either decreased or eliminated in such cultures (Fig. 2B, lanes 7,8,11,12). In conclusion, Sox9 is able to mimic the ability of Shh to induce robust somitic chondrogenesis, and induces this process with faster kinetics than does $\mathrm{Nkx} 3.2$. Whereas Sox9 and Nkx3.2 induce the expression of Ihh, Gli-1, and Patched, both Sox9 and Nkx3.2 can promote chondrogenesis independently of inducing hedgehog signaling, as administration of hedgehog blocking reagents did not block the ability of these transcription factors to induce somitic chondrogenesis.
BMP signaling is required for Sox9or Nkx3.2-mediated cartilage induction

Given that BMP signals are necessary to maintain somitic expression of Sox 9 following transient exposure to Shh, we asked if viral expression of Sox9 was able to bypass the requirement for BMPs in cartilage differentiation. In the absence of exogenous BMP2, RCAS (A)-Sox9 infection induced robust expression of aggrecan and epiphycan, but only trace levels of collagen IX and undetectable levels of Nkx3.2 and Ihh (Fig. 3A, cf. lanes 1 and

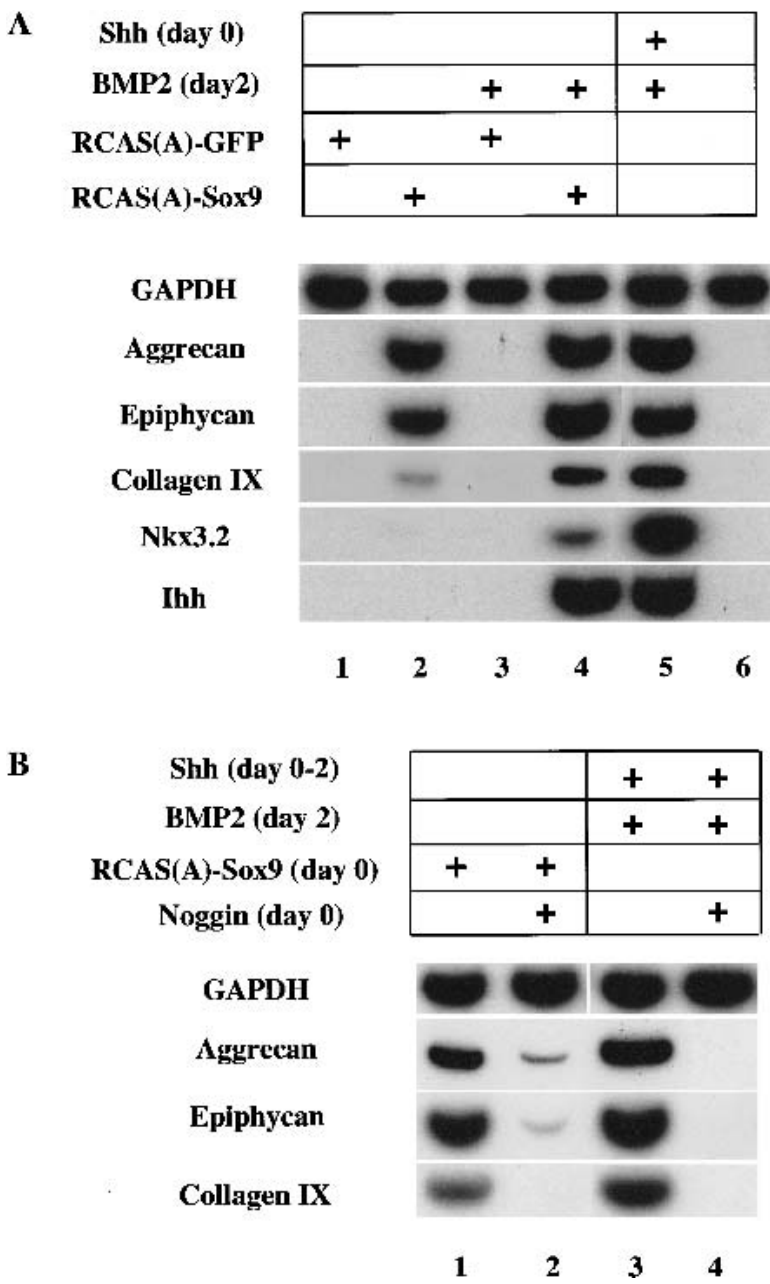

Figure 3. Sox 9 cooperates with BMP to induce robust chondrogenesis. (A) Explants of somite I-III were either infected with RCAS (A)-GFP (lanes 1,3) or RCAS (A)-Sox9 (lanes 2,4), or cultured in the presence of Shh $(500 \mathrm{ng} / \mathrm{mL}$; lane 5) or in control medium (lane 6). After $2 \mathrm{~d}$ in culture, BMP2 (100 ng/mL) was added to some of the explants (lanes 3-5) and the tissue was cultured for an additional $3 \mathrm{~d}$. After $5 \mathrm{~d}$ of culture, the tissue was harvested and gene expression was assayed by RT-PCR. (B) BMP is required for Sox9-induced chondrogenesis. Somites I-III were cultured in the presence of $3 \%$ FBS and either infected with RCAS (A)-Sox9 (lanes 1,2) or cultured in the presence of Shh $(0-2 \mathrm{~d})$ and BMP2 $(2-5 \mathrm{~d}$; lanes 3,4$)$. Conditioned medium from either control CHO cells (lanes 1,3) or Noggin-expressing cells (lanes 2,4) was added to the cultures. After $5 \mathrm{~d}$ of culture, the explants were harvested and processed for RT-PCR analysis. 
2). In contrast, when BMP2 was added $2 \mathrm{~d}$ following RCAS (A)-Sox9 infection, the explants expressed high levels of collagen IX, Nkx3.2, and Ihh when they were harvested after $5 \mathrm{~d}$ of culture (Fig. 3A, lane 4). Because somitic tissue expresses endogenous BMP4 when cultured after $3 \mathrm{~d}$ (Murtaugh et al. 1999), we wondered if Sox9-mediated induction of aggrecan and epiphycan was dependent upon endogenous BMP signals. To block endogenous BMP signaling, we cultured the explants in the presence of the BMP-antagonist Noggin. In fact, application of Noggin to the explanted cultures greatly reduced the expression of aggrecan and epiphycan induced by ectopic Sox9 (Fig. 3B, cf. lanes 1 and 2) and completely eliminated that induced by Shh/BMP2 administration (Fig. 3B, cf. lanes 3 and 4). Together, these findings indicate that Sox9-mediated chondrogenesis requires BMP signals and that expression of early chondrocyte differentiation markers such as aggrecan and epiphycan requires less BMP signaling than does expression of genes such as Nkx3.2, Ihh, and collagen IX.

\section{Reciprocal induction of Sox 9 and Nkx3.2 represents a chondrogenic positive regulatory loop}

In light of the fact that Nkx3.2 can induce somitic chondrogenesis (Murtaugh et al. 2001), it was of interest that Sox 9 induced both the expression of endogenous Nkx3.2 and somitic chondrogenesis (Fig. 3A, lane 4). We wondered if Nkx3.2 might reciprocally induce the expression of Sox 9 and thereby generate an autoregulatory loop that acts to maintain the expression of both genes. Consistent with this notion, we found that in the presence of BMP2, ectopic Nkx3.2 induced the expression of endogenous Sox9 (Fig. 4A, lanes 4,8) to levels equivalent to that seen following exposure of psm to Shh followed by BMP2 (Fig. 4A, lane 9). Our findings indicate that Nkx3.2 and Sox9 induce one another's synthesis; therefore, these genes constitute a prochondrogenic positive regulatory loop.

Prior work has established that Nkx3.2 induces somitic chondrogenesis by acting as a transcriptional repressor (Murtaugh et al. 2001). To determine if activation of Sox 9 expression by Nkx3.2 similarly requires the transcriptional repressor function of $\mathrm{Nkx} 3.2$, we analyzed Sox 9 expression in presomitic mesoderm explants infected with retroviruses encoding various mutants of Nkx3.2. In contrast to wild-type Nkx3.2, expression of a

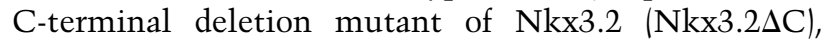
which lacks a C-terminal transcription repression domain (Murtaugh et al. 2001), failed to induce both Sox9 gene expression or somitic chondrogenesis (Fig. 4B, cf. lanes 2 and 4). However, when the Engrailed transcription repression domain was appended onto $\mathrm{Nkx} 3.2 \Delta \mathrm{C}$, the chimeric transcription factor (termed Nkx3.2 $\Delta \mathrm{C}$-Engrailed) regained its ability to induce both Sox 9 gene expression and other cartilage differentiation markers (Fig. 4B, lane 6). Therefore, induction of both Sox9 and cartilage differentiation markers by Nkx3.2 requires the ability of this factor to function as a transcriptional repressor. These findings suggest that forced expression of
Nkx3.2 activates the expression of Sox9 by blocking the synthesis of a transcriptional inhibitor of this latter gene.

To assay if Nkx3.2 is able to induce the expression of Sox9 in vivo, we infected the wing bud on one side of E3 (stage 17-19) chick embryos with RCAS-Nkx3.2. The embryos were harvested $7 \mathrm{~d}$ postinfection, the wings were sectioned in a cryostat, and in situ hybridization was performed on serial sections to detect both Sox 9 and collagen IX expression. In uninfected limbs, Sox 9 and collagen IX expression is restricted to immature chondrocytes that lie adjacent to the articular region of developing bones (Fig. 4C, panels A,C) and overlaps the expression domain of Nkx3.2 (data not shown). In contrast, in RCAS-Nkx3.2-infected limbs, both Sox9 and collagen IX are expressed throughout the entire developing bone, even at locations that are distant from the periarticular cartilage (Fig. 4C, panels B,D). Thus, viral $\mathrm{Nkx} 3.2$ misexpression is able to expand the expression of Sox9 into regions of the developing bone that would usually lack expression of this gene.

\section{A reverse-function mutant of $N k x 3.2$ can block the induction of Sox9 and cartilage gene expression by Shh/BMP signals}

The above experiments indicate that Nkx3.2 is sufficient to activate the expression of Sox9 in both somitic explants and in ovo, but do not address if Nkx3.2 is required for Sox9 expression. To investigate this issue, we used a reverse-function mutant of $\mathrm{Nkx} 3.2, \quad \mathrm{Nkx} 3.2$ VP16, in which the transcriptional activation domain of VP16 has been appended onto Nkx3.2, and thus turns Nkx3.2 from being a transcriptional repressor into a transcriptional activator (Murtaugh et al. 2001). Prior work has indicated that Nkx3.2-VP16 has opposite effects to wild-type Nkx3.2, and can block the formation of axial cartilage following viral misexpression in ovo (Murtaugh et al. 2001). Consistent with these in vivo findings, infection of somitic explants with RCASNkx3.2-VP16 repressed the induction of Sox9, aggrecan, epiphycan, collagen IX, and endogenous Nkx3.2 following Shh/BMP4 administration (Fig. 4D, lanes 2,4). Therefore, expression of a reverse-function form of Nkx3.2 blocks the induction of Sox 9 and cartilage formation induced by sequential Shh and BMP signals.

\section{Sox9 and Nkx3.2 promote BMP-dependent proliferation and survival of chondrocytes}

We have consistently observed that regimens that promote somitic chondrogenesis such as administration of Shh followed by BMP2, or expression of either Sox9 followed by BMP2, or Nkx3.2 followed by BMP2, result in an increased number of cells in the cultured explants. Although the mitogenic and anti-apoptotic activities of Shh are well established (Teillet et al. 1998; Borycki et al. 1999; Marcelle et al. 1999; Britto et al. 2000), we were curious to evaluate if Sox 9 and/or Nkx3.2 might also promote the proliferation or survival of somitic cells. To 
Zeng et al.

A

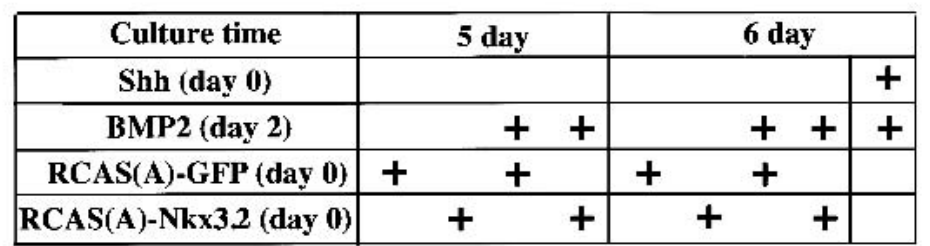

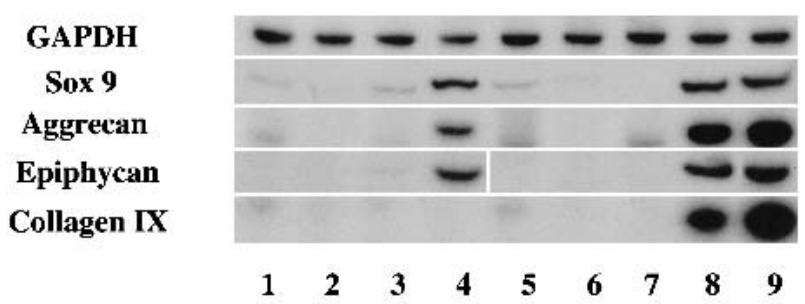

B

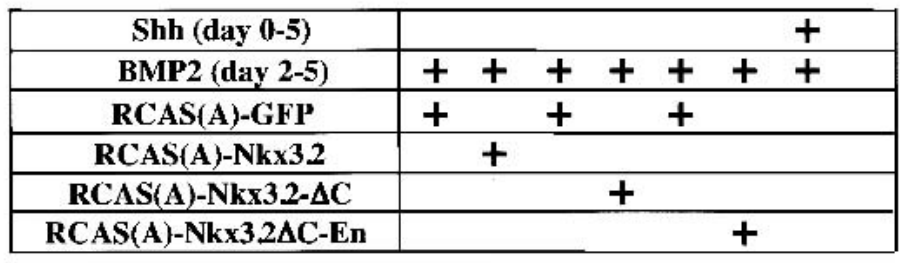

\section{GAPDH \\ Sox 9 \\ Aggrecan \\ Epiphycan \\ Collagen IX}

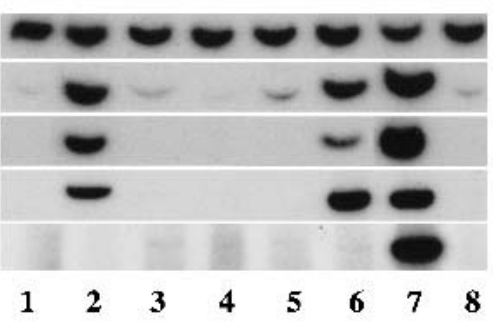

D

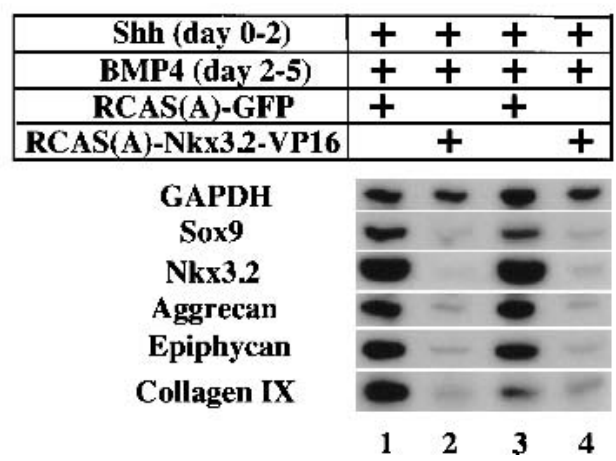

Figure 4. Nkx3.2 induces the expression of Sox9. (A) Nkx3.2 cooperates with BMP2 to induce Sox9 expression and chondrogenic differentiation. Presomitic mesoderm explants were either infected with RCAS (A)-GFP (lanes 1,3,5,7) or RCAS (A)-Nkx3.2 (lanes 2,4,6,8), or cultured in the presence of Shh (lane 9). After $2 \mathrm{~d}$ in culture, BMP2 was added to some of the explants (lanes 3,4,7-9) and the tissues were cultured for either $5 \mathrm{~d}$ (lanes 1-4) or $6 \mathrm{~d}$ (lanes 5-9). Gene expression was assayed by RT-PCR. (B) Nkx3.2 induces Sox9 expression by acting as a transcriptional repressor. Presomitic mesoderm explants were either infected with RCAS(A)-GFP (lanes

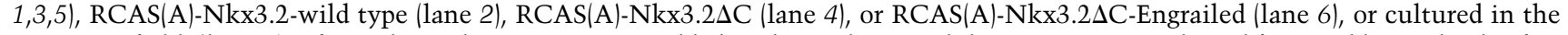
presence of Shh (lane 7). After $2 \mathrm{~d}$ in culture, BMP2 was added to the explants and the tissues were cultured for an additional $3 \mathrm{~d}$. After $5 \mathrm{~d}$ of culture, the explants were harvested and processed for RT-PCR analysis. $(C)$ Ectopic Nkx3.2 expands the domain of Sox9 and collagen IX expression in developing cartilage in vivo. RCAS (A)-Nkx3.2 virus was injected into the right wing bud of an E3 chick embryo (stages 17-19). The infected embryo was fixed at E10 after injection and in situ hybridization for Sox9, and collagen IX was performed on serial sections $(B, D)$. Expression of Sox9 and Collagen IX is shown in the uninjected left limb as a control $(A, C)$. $(D)$ A reverse-function form of Nkx3.2 can block Shh/BMP4 induction of Sox9 and somitic chondrogenesis in vitro. Presomitic mesoderm and somites I-III were infected with either RCAS(A)-GFP virus (lanes 1,3) or with RCAS(A)-Nkx3.2-VP16 virus (lanes 2,4) and cultured with Shh $(500 \mathrm{ng} / \mathrm{mL})$ for $2 \mathrm{~d}$ and BMP4 $(100 \mathrm{ng} / \mathrm{mL})$ for the next $3 \mathrm{~d}$. After $5 \mathrm{~d}$ of culture, the explants were harvested and assayed for gene expression by RT-PCR. 
investigate if Sox9 or Nkx3.2 promotes the proliferation of somitic cells, we infected somites I-III with RCASSox9, RCAS-Nkx3.2, or RCAS-alkaline phosphatase (RCAS-AP), and added BMP2 after the first $2 \mathrm{~d}$ of culture (referred to as Sox9+BMP2, Nkx3.2+BMP2, and $\mathrm{AP}+\mathrm{BMP} 2$, respectively). At the last day of culture, the explants were pulsed with BrdU for $6 \mathrm{~h}$, and the cultures were harvested for immunocytochemistry. To investigate if Sox9 or Nkx3.2 promotes the survival of somitic cells, we analyzed apoptosis in the cultured explants by TUNEL assay. For comparison, we also examined proliferation and apoptosis in somitic explants that had been maintained in control medium, treated with Shh for the entire culture period, or treated with Shh for $2 \mathrm{~d}$ followed by BMP2 for the rest of the culture period (referred to as Shh + BMP2).

A photograph showing BrdU-positive cells in the various explants is depicted in Figure 5A. Because the total number of cells present in each explant varied, we quantified the amount of proliferation and apoptosis in the various cultures by measuring the percentage of cells that had either incorporated BrdU (Fig. 5B) or showed TUNEL staining (Fig. 5C). Whereas explants cultured in control medium showed low levels of BrdU incorporation (12\%; Fig. 5A, panel A1; Fig. 5B) and high levels of apoptosis as detected by TUNEL assay (88\%; Fig. 5C), those cultured in either the presence of Shh or Shh + BMP2 showed high levels of BrdU incorporation $(42 \%$ and $52 \%$, respectively; Fig. 5A, panels B1,C1; Fig. $5 \mathrm{~B})$ and low levels of apoptosis $(12 \%$ and $5 \%$, respectively; Fig. 5C). These results indicate that prochondrogenic conditions following Shh or Shh + BMP2 administration support somitic cell proliferation and survival.

Expression of AP + BMP2 failed to support either increased proliferation or survival of infected explant cultures (Fig. 5A, panel D1; Fig. 5B,C). In contrast, expression of either Sox9 + BMP2 or Nkx3.2 + BMP2 led to a substantial increase in BrdU incorporation $138 \%$ and 24\%, respectively; Fig. 5A, panels E1,F1; Fig. 5B) and a striking decrease in apoptosis $(2 \%$ and $5 \%$, respectively; Fig. $5 \mathrm{C}$ ) in these cultures. To evaluate if Nkx3.2 promotes somitic cell proliferation and survival by acting as a transcriptional repressor, we evaluated BrdU incorporation and apoptosis in cultures infected with either RCAS-Nkx3.2DC followed by BMP2 at day 2 $(\mathrm{Nkx} 3.2 \Delta \mathrm{C}+\mathrm{BMP} 2)$ or infected with RCAS-Nkx3.2 $\mathrm{C}$ -

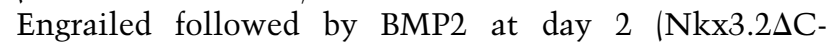
$\mathrm{En}+\mathrm{BMP} 2)$. Whereas expression of $\mathrm{Nkx} 3.2 \Delta \mathrm{C}+\mathrm{BMP} 2$ showed a decreased ability to both promote cell proliferation and block apoptosis as compared with $\mathrm{Nkx} 3.2$ (wild type) + BMP2 (Fig. 5A, cf. panels F1 and G1; Fig. $5 \mathrm{~B}, \mathrm{C})$, expression of Nkx3.2 $\Delta \mathrm{C}-\mathrm{En}+\mathrm{BMP} 2$ showed a very robust induction of cell proliferation and inhibition of apoptosis (Fig. 5A, panel H1; Fig. 5B,C). Thus, Nkx3.2 requires a transcriptional repression domain to promote somitic cell proliferation, survival, and chondrogenic differentiation.

Because forced expression of either Sox 9 or $\mathrm{Nkx} 3.2$ can induce the expression of Ihh in somites cultured in BMP2 (Fig. 2), we wondered if these transcription factors might be driving somitic cell proliferation and survival by indirectly inducing the hedgehog signaling pathway. To understand if hedgehog signaling is necessary for Sox 9 and Nkx3.2 to induce somitic cell proliferation and survival, we applied cyclopamine to the somitic explants treated with the various regimens discussed above. Administration of cyclopamine completely blocked the ability of Shh or Shh + BMP2 to increase cell proliferation or decrease apoptosis (Fig. 5A, panels B2,C2; Fig. $5 \mathrm{~B}, \mathrm{C})$. In striking contrast, administration of cyclopamine did not blunt the ability of Sox9 + BMP2, $\mathrm{Nkx} 3.2+\mathrm{BMP} 2$, or Nkx3.2AC-En + BMP2 to either increase cell proliferation or block apoptosis (Fig. 5A, panels E2,F2,H2; Fig. 5B,C). Thus, Sox9 and Nkx3.2 are able to promote cell proliferation and survival in the absence of hedgehog signaling.

We have found that a transient exposure of presomitic mesoderm to Shh for $2 \mathrm{~d}$ is sufficient to enable subsequent BMP signals to induce chondrogenesis (Murtaugh et al. 1999). Thus, after an initial priming stage, Shh signals are no longer necessary to promote BMP-dependent chondrogenesis. We wondered if the effects of Shh on somitic cell proliferation and survival similarly require only a transient exposure to Shh. To address this question, we cultured somitic mesoderm with Shh for 2 $\mathrm{d}$, and subsequently cultured the explants in medium containing either cyclopamine alone or cyclopamine plus BMP2 for an additional $5 \mathrm{~d}$ of culture. At the last day of culture, explants were pulsed with BrdU. Explants cultured in Shh for $2 \mathrm{~d}$ and in medium containing cyclopamine for a subsequent $5 \mathrm{~d}$ showed a relatively low level of BrdU incorporation (10\% of cells), but explants that were exposed transiently to Shh and subsequently cultured in medium containing both cyclopamine and BMP2 showed a significantly greater level of BrdU incorporation (37\% of cells; Fig. 5D). As BMP2 administration alone did not significantly affect BrdU incorporation in the somitic explant (Fig. 5D), these results indicate that transient exposure of somitic mesoderm to Shh renders subsequent BMP signals mitogenic in the absence of continued hedgehog signaling. This result differs from that shown in Figure $5 \mathrm{~B}$, in which proliferation by Shh + BMP2 was totally inhibited when cyclopamine was applied at the beginning of the culture period. Because Shh induces the expression of both Sox9 and Nkx3.2 by $2 \mathrm{~d}$ of culture (Fig. 1A), and subsequent BMP signals can maintain the expression of these genes (Fig. $1 \mathrm{~B})$, we reasoned that maintained expression of these two genes may account for the ability of subsequent BMP signals to promote proliferation of somitic cells. Indeed, either Sox 9 or Nkx3.2, in the presence of BMP, was able to promote cell proliferation in somite explants, even in the presence of cyclopamine (see Fig. 5B). Because induction of chondrogenesis by Sox 9 and Nkx3.2 requires concomitant BMP signaling we asked if BMP signals are similarly required for Sox 9 and $\mathrm{Nkx} 3.2$ to induce cell proliferation. Although RCAS-Sox9 or RCAS-Nkx3.2 in the absence of exogenous BMP2 failed to significantly increase BrdU incorporation in infected somites, expression of viral-encoded Sox 9 or Nkx3.2 in 
Zeng et al.

A

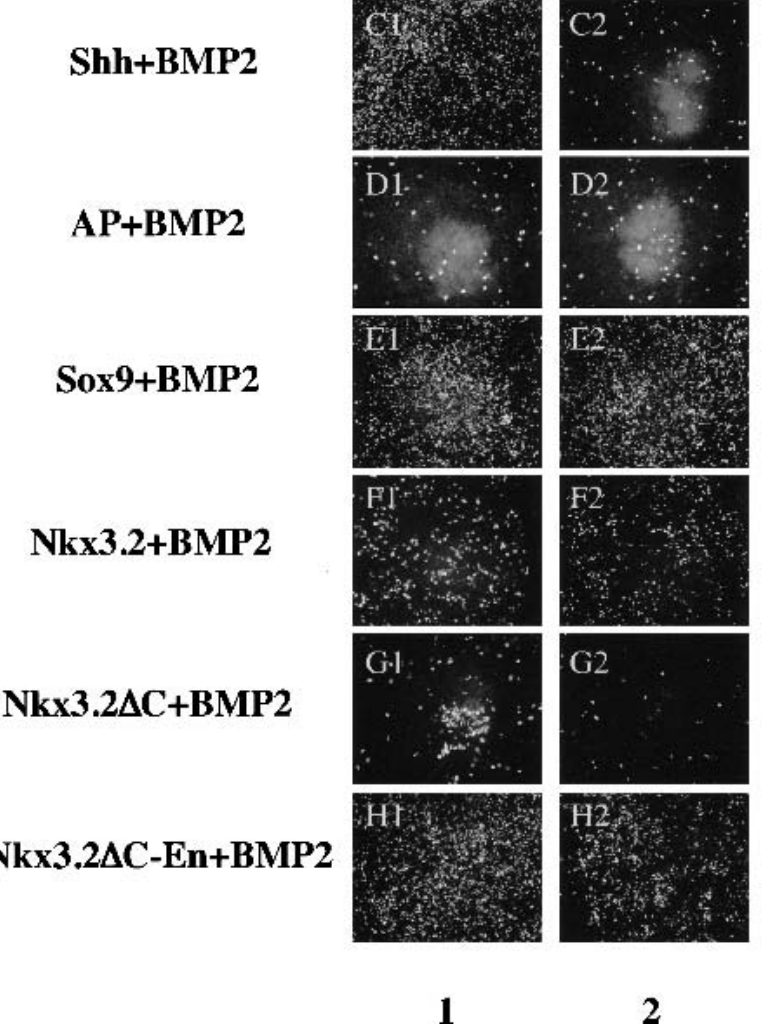

B

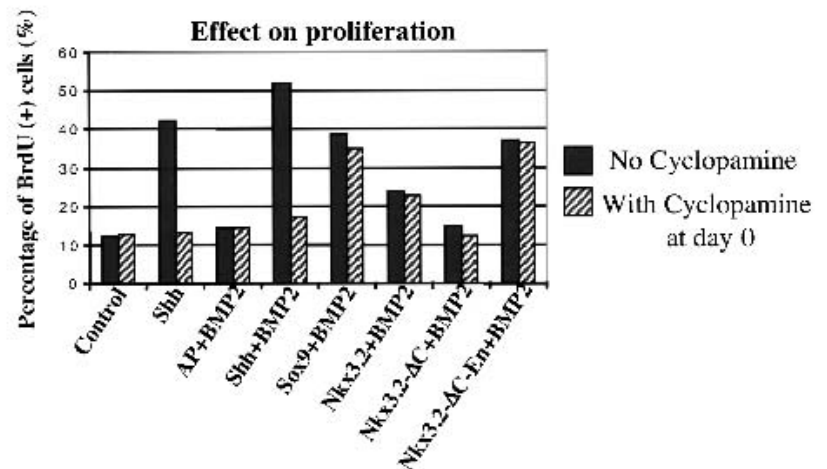

$\mathrm{C}$

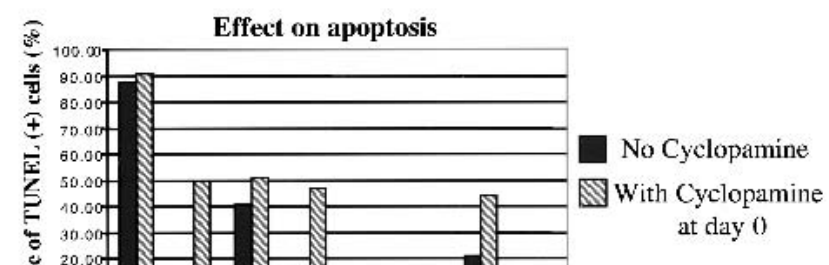

Figure 5. Sox 9 and Nkx3.2 promote cell proliferation and survival in the presence of BMP signals. (A) Somites I-III from stage 10 chick embryos were either incubated in medium only (A1,A2), medium plus Shh (B1,B2), medium plus Shh for 2 d followed by BMP2 for 5 $\mathrm{d}(\mathrm{C} 1, \mathrm{C} 2)$, or infected with either RCAS(A)-alkaline phosphatase (AP) followed by BMP2 (D1,D2), RCAS(A)-Sox9 followed by BMP2

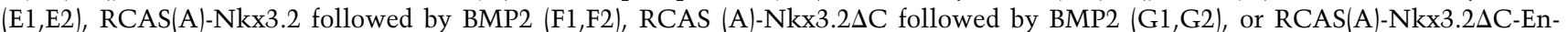
grailed followed by BMP2 $(\mathrm{H} 1, \mathrm{H} 2)$. Shh $(500 \mathrm{ng} / \mathrm{mL})$ was present where indicated throughout the entire culture period. BMP2 (100 $\mathrm{ng} / \mathrm{mL}$ ) was present where indicated for the last $5 \mathrm{~d}$ of culture. All RCAS(A) viral infections were initiated on day 0 . The explants were incubated in either the absence (column 1) or presence (column 2) of cyclopamine during the entire culture period. After $7 \mathrm{~d}$ of culture the explants were analyzed for either proliferation by BrdU labeling (Fig. 5A,B) or for apoptosis by TUNEL staining (Fig. 5C). (B) The effect of the various regimens on somitic cell proliferation was quantified by the percentage of BrdU-positive cells in each explant. $(C)$ The effect of the various regimens on apoptosis was quantified by the percentage of TUNEL-positive cells in each explant. (D) Sox 9 and Nkx3.2 stimulate somitic cell proliferation in a BMP-dependent fashion. Explants containing somites I-III were exposed to Shh (days 0-2) followed by cyclopamine (days 2-7), or Shh (days 0-2) followed by BMP2 + cyclopamine (days 2-7), or infected with RCAS(A)-GFP, RCAS(A)-Sox9, or RCAS(A)-Nkx3.2 and cultured in either the absence or presence of BMP2 as indicated. On the last day, the cultures were pulsed with BrdU, and the percent of BrdU-positive cells was determined for each regimen.

the presence of BMP2 markedly boosted BrdU incorporation (Fig. 5D). In summary, these findings indicate that forced expression of Sox 9 and Nkx3.2 can both promote somitic cell proliferation and survival, provided that
BMP signals are present. Whereas these effects on somitic cell proliferation and survival mimic the effects of Shh on somitic cells, cell proliferation and survival induced by either Sox9 + BMP2 or Nkx3.2 + BMP2 are 
not blocked by cyclopamine and therefore not mediated by the hedgehog signaling pathway.

\section{Sox9 induces de novo chondrogenesis in tissue that is not fated to give rise to chondrocytes}

We wondered if the ability of either Sox9 or Nkx3.2 to induce chondrogenesis in explants of presomitic mesoderm reflected the ability of these transcription factors either to induce the expansion of a prechondrogenic precursor population within this tissue or to induce formation of chondrocytes de novo. Indeed, this tissue has been in close proximity to both the notochord and floor plate prior to removal from the embryo, and it is possible that Shh signals from these ventral midline tissues may have already induced sclerotomal precursors that are destined to give rise to chondrocytes. To clarify if Sox9 or Nkx3.2 specifically amplifies a preexisting population of chondrocyte progenitors, we turned to a tissue that will never form cartilage: the posterior lateral-plate mesoderm and ectoderm from stage 5-6 chick embryos. This tissue has been fate-mapped to give rise to blood and outer epithelium (Schoenwolf et al. 1992; Marvin et al. 2001). In the presence of exogenous BMP2, forced expression of retroviral Sox 9 in posterior lateral-plate mesoderm and ectoderm induced robust expression of Nkx3.2, aggrecan, epiphycan, and collagen IX (Fig. 6, lane 2). In contrast, expression of retroviral Nkx3.2 or treatment of this tissue with Shh followed by BMP2 failed to induce the expression of any chondrogenic markers (Fig. 6, lanes 4,6). These findings indicate that, in the presence of BMP signals, Sox9 is able to induce cartilage formation in noncartilaginous tissues, but forced expression of $\mathrm{Nkx} 3.2$ or Shh administration fails to elicit this effect. Because RCAS-Sox9 infection is able to induce chondrogenesis in presumptive lateral-plate tissue, it strongly suggests that forced expression of Sox9 is able to induce the de novo formation of chondrocytes. In contrast, the inability of either RCAS-Nkx3.2 infection or Shh administration to initiate chondrogenesis in posterior lateral-plate tissue suggests that somitic mesoderm may be uniquely suited to activate the chondrogenic program in response to these regimens.

To address why Shh followed by BMP2 was unable to induce chondrogenesis in posterior lateral-plate tissue, we examined whether the Shh signal transduction is operative in this tissue by assaying the expression of the Shh target genes Gli-1 and Patched. Interestingly, both Gli-1 and Patched were induced in posterior lateral-plate tissue by Shh and Sox9, but not by Nkx3.2 (Fig. 6, cf. lanes 2, 4, and 6). This suggests that lateral plate mesoderm and ectoderm can transduce a hedgehog signal, but that additional factors, not present in this tissue, are necessary for either hedgehog signals or ectopic Nkx3.2 to induce the expression of Sox 9 and initiate subsequent chondrogenesis. Alternatively, it is equally possible that an inhibitor is present in the lateral-plate tissue that prevents Shh or Nkx3.2 from inducing the synthesis of Sox9.

\begin{tabular}{|c|c|c|c|c|c|}
\hline Shh (day0) & & & & & + \\
\hline BMP2 (day2) & $+\quad+$ & + & + & + & + \\
\hline RCAS(A)-GFP & + & + & & & \\
\hline RCAS(A)-Sox 9 & + & & & & \\
\hline RCAS(A)-Nkx3.2 & & & + & & \\
\hline
\end{tabular}

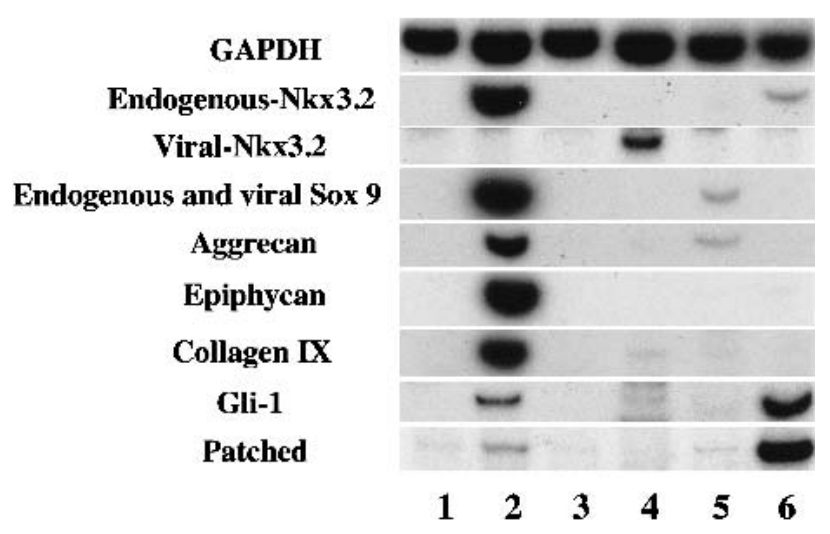

Figure 6. Sox 9 is able to induce de novo chondrogenesis in a non-cartilage-forming tissue, but Nkx3.2 or Shh cannot elicit this effect. Posterior lateral-plate mesoderm and ectoderm from stage 5-6 chick embryos was either infected with RCAS(A)-GFP (lanes 1,3), RCAS(A)-Sox9 (lane 2), or RCAS(A)-Nkx3.2 (lane 4), or incubated with control medium (lane 5), or treated with 500 $\mathrm{ng} / \mathrm{mL}$ Shh (lane 6). After $2 \mathrm{~d}$ in culture, BMP2 was added to the explants and the tissue was cultured an additional $3 \mathrm{~d}$. After $5 \mathrm{~d}$ of culture, the explants were harvested and processed for RTPCR analysis.

\section{Discussion}

Our prior work (Murtaugh et al. 1999) and that of others (Chiang et al. 1996) have established that Shh induces a competence in somitic cells for subsequent BMP signals to activate the chondrocyte differentiation program. Shh seems to initiate chondrogenic competency in the paraxial mesoderm by inducing the expression of both Nkx3.2 and Sox9. Forced expression of either of these transcription factors in paraxial mesoderm can activate the chondrogenic differentiation program, provided that BMP signals are also present. Once induced by Shh, BMP signals can maintain the expression of both Sox 9 and Nkx3.2. Our findings suggest that BMP-mediated maintenance of Sox9 and Nkx3.2 gene expression may rely upon an autoregulatory loop between these two transcription factors, as Sox9 and Nkx3.2 reciprocally induce one another's expression in the presence of BMP signals. Consistent with such a mutually reinforcing regulatory loop, mice embryos mutant for the murine Nkx3.2 homolog Bapx show reduced expression of Sox 9 in the ventral medial sclerotome (Lettice et al. 1999; Tribioli and Lufkin 1999; Akazawa et al. 2000). In addition to the positive regulatory loop between Nkx3.2 and Sox9, Sox9 may also be capable of maintaining its own expression, as ectopic expression of exogenous Sox9 in ATDC5 cells 
can activate the expression of endogenous Sox9 (D.W. Kim and A.B. Lassar, unpubl.). Surprisingly, ectopic Nkx3.2 induces the expression of both Sox9 and chondrogenic markers by acting as a transcriptional repressor (this work; Murtaugh et al. 2001). Indeed, infection of paraxial mesoderm with Nkx3.2-VP16, which is a transcriptional activator and presumably activates the expression of genes usually repressed by Nkx3.2-wild type, blocks axial chondrogenesis in vivo (Murtaugh et al. 2001) and represses Shh/BMP4-mediated activation of Sox 9 in presomitic mesoderm in vitro (this work). Thus, we speculate that $\mathrm{Nkx} 3.2$ indirectly activates Sox9 expression and induces somitic chondrogenesis by blocking the synthesis of an inhibitor of Sox 9 expression. Because Sox9 can reciprocally induce the expression of Nkx3.2, Sox9 may activate its own synthesis by inducing Nkx3.2 and thereby down-regulate an inhibitor(s) of its own expression (outlined in Fig. 7). Although our gain- and loss-of-function experiments indicate that a Nkx3.2/Sox9 regulatory circuit is possible, the physiological importance of this circuit will await both the

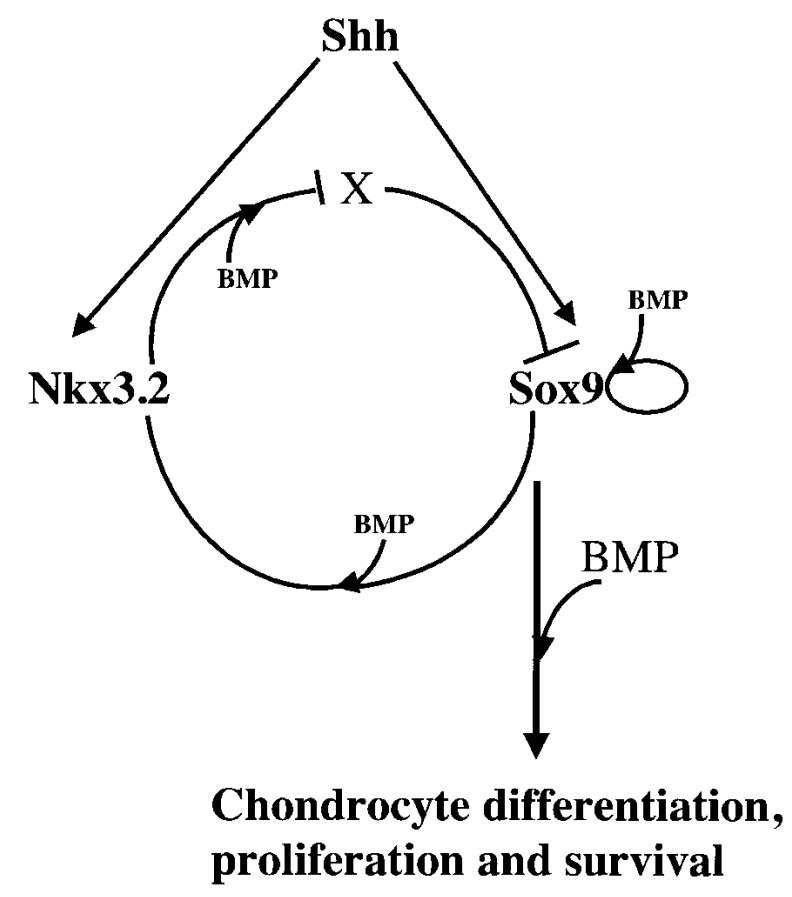

Figure 7. Shh initiates a positive regulatory loop between Sox9 and Nkx3.2 that is maintained by BMP signaling. Shh from the notochord and floor plate induces the expression of Sox9 and $\mathrm{Nkx} 3.2$ in the sclerotome. In the presence of subsequent BMP signals, Nkx3.2 represses the synthesis of an inhibitor of Sox9 gene expression (termed $\mathrm{X}$ in the diagram). Furthermore, in the continued presence of BMP signals, Sox 9 can maintain both its own expression and that of $\mathrm{Nkx} 3.2$, and induce the expression of cartilage differentiation markers such as aggrecan, epiphycan, collagen IX, and Indian hedgehog. Thus Sox9 and Nkx3.2 compose a positive regulatory loop that acts to maintain the continued expression of these genes in the absence of continued Shh signaling. Moreover, these two factors confer the competence for somitic cells to undergo BMP-dependent chondrogenesis and proliferation in the absence of Shh signaling. identification of direct Nkx3.2 target genes and an elucidation of the promoter elements necessary to sustain the expression of both Nkx3.2 and Sox9.

\section{Sox9, but not Nkx3.2, can induce chondrogenesis in non-cartilage-forming tissues}

An important difference that we noted between the chondrogenic potencies of Sox 9 and $\mathrm{Nkx} 3.2$ was that whereas ectopic expression of either Sox 9 or $\mathrm{Nkx} 3.2$ could activate chondrogenesis in paraxial mesoderm, only Sox9 was able to activate this differentiation program in non-cartilage-forming tissues. We observed that explanted somites, when treated with BMP2 (for the last $3 \mathrm{~d}$ of culture), frequently expressed low levels of aggrecan and epiphycan in the absence of prior Shh treatment. Thus, we speculate that this tissue is somehow predisposed to activate the chondrogenic differentiation program, and that ectopic Nkx3.2 expression might be able to activate chondrogenesis in somitic cells by either derepressing a cryptic chondrogenic program or by amplifying a selected population of cartilage precursors. To further address this issue, we turned to a tissue that does not give rise to cartilage: posterior lateral-plate mesoderm and ectoderm from stage 5-6 chick embryos. Posterior lateral-plate mesoderm has been shown by lineage mapping to give rise to blood, whereas the ectoderm will become part of the outer epithelium (Schoenwolf et al. 1992). Although ectopic Sox9 was able to activate robust cartilage formation in this tissue, Nkx3.2 was unable to induce chondrocyte gene expression in this tissue. This finding suggests that Sox9 is able to activate de novo chondrogenesis, but $\mathrm{Nkx} 3.2$ can only do so in certain tissue contexts.

What is unique to somitic mesoderm that allows Nkx3.2 to initiate the chondrogenic differentiation program? We have found that, when cultured in the presence of BMP2, this tissue expresses low levels of Sox9. We speculate that $\mathrm{Nkx} 3.2$ expression may up-regulate this low-level expression of Sox 9 by blocking the synthesis of an inhibitor of Sox9 gene expression in the somitic cells. In this scenario, high-level expression of Sox9 in paraxial mesoderm is repressed by an inhibitor, factor X (see Fig. 7). Nkx3.2 blocks the synthesis of factor $\mathrm{X}$ and thereby derepresses the expression of Sox 9 in paraxial mesoderm. The lateral-plate mesoderm may contain other inhibitors of Sox9 expression that Nkx3.2 is unable to repress. Alternatively, it is possible that Nkx3.2 expands a population of Sox9-positive chondrogenic progenitor cells that are present in presomitic mesoderm by specifically increasing cell proliferation or preventing cell death of these prechondrocytes.

Our finding that Sox9 can initiate chondrogenesis in a tissue not normally fated to give rise to cartilage is consistent with prior findings that ectopic expression of Sox9 in the branchial arches or in the hindbrain can induce collagen II expression at these sites (Bell et al. 1997). Furthermore, cells null for Sox 9 were found to be excluded from cartilaginous tissues, strongly suggesting an absolute requirement for Sox 9 in cartilage formation 
(Bi et al. 1999). Sox9 probably directly activates at least some cartilage differentiation markers as Sox 9 has been shown to bind to the promoters for collagen II and aggrecan (Bell et al. 1997; Lefebvre et al. 1997, 1998; Ng et al. 1997; Zhou et al. 1998; Sekiya et al. 2000). However, it has also been reported that Sox9 does not activate cartilage differentiation markers in cell lines that do not express low levels of endogenous Sox9 or collagen IIa (Lefebvre et al. 1998), suggesting that tissue restricted cofactors are necessary for Sox9-mediated chondrogenesis. Indeed, elegant work by Lefebvre et al. (1998) has shown that Sox9 synergizes with L-Sox5 and Sox6 to activate expression of the collagen IIa promoter and promote robust chondrogenesis. Mice engineered to lack both L-Sox5 and Sox6 have severe skeletal defects and show very little expression of cartilage structural genes (Smits et al. 2001). It will be interesting to determine whether ectopic expression of Sox9 induces chondrogenic differentiation by activating the synthesis of these other Sox family members.

\section{Different classes of chondrocyte differentiation markers show differing requirements for BMP signals}

Chondrocyte differentiation is marked by a stereotypic sequence of gene expression in the maturing cartilage. One of the first genes to be expressed in developing cartilage is Sox9, whose expression slightly proceeds Nkx3.2/Bapx expression in long bones and is coincident with that of Nkx3.2/Bapx in the vertebrae (L.C. Murtaugh and A.B. Lassar, unpubl.). As cartilage matures, the expression of aggrecan, epiphycan, and collagen IX is initiated. In cartilage undergoing chondrocyte hypertrophy, markers of immature chondrocyte gene expression are extinguished (Glumoff et al. 1994; Johnson et al. 1999) and the transcription factor Cbfal is expressed, which plays an important role in the subsequent expression of collagen $\mathrm{X}$ in at least some skeletal elements (Komori et al. 1997; Inada et al. 1999; Kim et al. 1999; Takeda et al. 2001; Ueta et al. 2001). We have found that different cartilage genes seem to have different requirements for BMP signals. Whereas Sox9 induced the expression of aggrecan and epiphycan in the absence of exogenous BMP4, it could activate collagen IX and Nkx3.2 only when exogenous BMP4 was administered. Because a low level of BMP4 is autonomously expressed during the culture period (Murtaugh et al. 1999), this low level of endogenous BMP4 could be sufficient to cooperate with Sox9 to induce the expression of aggrecan and epiphycan. Yet, for collagen IX and Nkx3.2 to be induced by Sox9, exogenous BMP4 had to be applied to the culture medium. Therefore, a low level of BMP signaling may be sufficient to support the expression of aggrecan and epiphycan, whereas a higher level of BMP signaling is apparently necessary to support the expression of collagen IX and Nkx3.2. Consistent with this theory, we found that administration of the BMP-antagonist Noggin to Sox9-infected explants reduced the expression of aggrecan and epiphycan and eliminated the expression of collagen IX.
In addition to a differential dependency on BMP signaling, we have found that various chondrogenic markers are expressed with vastly differing kinetics. We have found that in presomitic mesoderm explants, regimens that induce chondrogenesis (i.e., Shh administration, or forced expression of Sox 9 or Nkx3.2) induce rapid expression of aggrecan and epiphycan and relatively delayed expression of collagen IX. This differential time course of gene expression suggests that aggrecan and epiphycan may be directly induced by Sox9, whereas collagen IX expression may require a second tier of induced transcriptional regulators.

\section{Sox9 and Nkx3.2 promote BMP-dependent somitic cell survival and proliferation}

We have found that transient exposure of presomitic mesoderm to Shh for $2 \mathrm{~d}$ renders subsequent BMP signals both mitogenic and anti-apoptotic. As such subsequent BMP signals maintain the expression of both Sox9 and Nkx3.2, it seems plausible that these transcription factors may play a role in maintaining sclerotome survival and proliferation. Consistent with this hypothesis, we have found that expression of retrovirally encoded Sox 9 or Nkx3.2 can promote both the survival and proliferation of somitic cells if BMP signals are provided. Because BMP signals are similarly necessary for both of these factors to induce somitic chondrogenesis, it is not clear if these genes either directly affect somitic cell proliferation and survival or, rather, induce the synthesis of a chondrogenic intermediate that promotes these effects. On the other hand, it is clear that Ihh, which is induced by either Sox 9 or Nkx3.2 in the presence of BMP signals, is not necessary for these transcription factors to promote somitic cell survival and proliferation, as both these transcriptional regulators can promote these effects in the presence of the hedgehog signaling antagonist, cyclopamine.

Several elegant studies using genetically engineered mice have shown that Ihh signals play a crucial role in maintaining chondrocyte proliferation in the growth plate (St-Jacques et al. 1999; Long et al. 2001). Ihh is usually expressed in prehypertrophic chondrocytes (Vortkamp et al. 1996; Iwasaki et al. 1997; Pathi et al. 1999; Karp et al. 2000), and Ihh signaling is necessary both to maintain the expression of PTHrP in periarticular chondrocytes (Vortkamp et al. 1996; Karp et al. 2000) and to drive proliferation of prehypertrophic chondrocytes (Vortkamp et al. 1996; St-Jacques et al. 1999; Minina et al. 2001). Mice engineered to lack either Ihh or chondrocyte-specific expression of smoothened, a positive regulator of Ihh signaling, show a $50 \%$ reduction in chondrocyte proliferation in the growth plate (St-Jacques et al. 1999; Long et al. 2001). In addition to Ihh signals, work by Vortkamp and colleagues has indicated that BMP signals are required in parallel with Ihh to promote chondrocyte proliferation in the growth plate of developing bones (Minina et al. 2001). Our findings that either Sox9 or Nkx3.2 can induce chondrocyte survival and proliferation in the presence of BMP signals are consis- 
tent with these latter results and suggest that BMP signals may exert their mitogenic effect in the growth plate by modulating the activities of Nkx3.2, Sox9, or downstream target genes.

\section{The roles of other Shh-induced molecules} in sclerotome formation

Besides Sox9 and Nkx3.2, Pax1 and MFH1 are also expressed in the sclerotome (Deutsch et al. 1988; Neubuser et al. 1995; Winnier et al. 1997; Wilm et al. 1998) and are induced by Shh (Furumoto et al. 1999; L.C. Murtaugh, L. Zeng, and A.B. Lassar, unpubl.). Pax9 is expressed more laterally than Paxl in the sclerotome, and like Paxl, Pax9 also requires notochord for its expression (Neubuser et al. 1995). Unlike Sox9 or Nkx3.2, retroviral expression of Paxl in somitic explants is unable to induce cartilage formation (L. Zeng. and A.B. Lassar, unpubl.). Although MFH1 shows the same expression pattern as Nkx3.2 during sclerotome development (Winnier et al. 1997; Furumoto et al. 1999), retroviral expression of MFH1 in somite cultures similarly does not promote chondrogenesis (L. Zeng. and A.B. Lassar, unpubl.). Even though these factors may not be sufficient to initiate cartilage formation by themselves, it is still possible that they are required for the differentiation process. Indeed, their roles in axial chondrogenesis have been shown in the mice engineered to lack their expression. In Pax1 null embryos, ossification centers of vertebral bodies are absent or truncated, especially in the cervical region (Wilm et al. 1998). A more severe phenotype was observed in $P a x 1 / P a x 9$ double mutant embryos, where the ossification centers along the entire axis were lost $(\mathrm{Pe}-$ ters et al. 1999). Interestingly, both a lower rate of cell proliferation and increased apoptosis in the developing sclerotome seem to be responsible for the mutant phenotype (Peters et al. 1999). MFH1 null embryos also show skeletal defects, including decreased proliferation of sclerotomal cells and fused or absent ribs (Winnier et al. 1997). Furthermore, sclerotome cells are reduced in number and vertebral bodies develop poorly in Pax1/ MFH1 double homozygotes, apparently from reduced cell proliferation (Furumoto et al. 1999). Together with our own findings, these results suggest that Shh signals induce genes in paraxial mesoderm, such as Pax1, Pax9, and MFH1, that act to expand the number of sclerotomal cells, and genes such as Nkx3.2 and Sox9, that confer competence for subsequent BMP signals to both induce chondrocyte gene expression and maintain the survival and proliferation of committed chondrocytes. The combined action of these two classes of transcription factors ensures that a sufficient population of cells is available to both initiate and sustain the chondrogenic differentiation program.

\section{Materials and methods}

\section{Biological materials}

White leghorn chicken eggs were obtained from Spafas Inc. (North Franklin, CT). Dispase was purchased from Boehringer
Mannheim. N-terminus-Shh was produced as described previously (Murtaugh et al. 1999). BMP2 and BMP4 proteins were kind gifts from the Genetics Institute (Cambridge, MA). Noggin-conditioned medium was produced from $\mathrm{CHO}$ cells stably expressing Xenopus Noggin, which were kindly provided to us by Richard Harland (University of California, Berkeley). Control medium was produced from nontransfected $\mathrm{CHO}$ cells. RCAS (A)-GFP was kindly provided by Cliff Tabin (Harvard Medical School, Boston, MA). RCAS(A)-Nkx3.2 was generated as described (Murtaugh et al. 2001). RCAS(A)-Sox9 was kindly provided by Paul Sharp (Guy's hospital, London, UK; Healy et al. 1999). 5E1, the anti-Shh antibody, was purchased from Developmental Studies Hybridoma Bank. Cyclopamine and veratramine were kindly provided by W. Gaffield (Western Regional Research Center, Albany, CA; Incardona et al. 2000), and were used at concentrations of $500 \mathrm{nM}$.

\section{Embryo explant culture and viral infection}

Fertilized chicken eggs were incubated at $38^{\circ} \mathrm{C}$ before experimentation. Presomitic mesoderm or somites I-III was excised from stage 10 chick embryos in the presence of dispase $(10 \mathrm{mg} /$ $\mathrm{mL})$. The explants were cultured in a collagen gel in $\mathrm{S} / \mathrm{H}$ medium at $37^{\circ} \mathrm{C}$ as described (Murtaugh et al. 1999). In all the experiments, Shh was used at a concentration of $500 \mathrm{ng} / \mathrm{mL}$, and BMP2 or BMP4 was used at the concentration of $100 \mathrm{ng} / \mathrm{mL}$. For experiments involving Noggin, control or Noggin-conditioned medium was added as $1 / 4$ of the culture medium volume. For viral infection experiments, newly excised explants were incubated with $4 \mu \mathrm{L}$ of concentrated virus $\left(10^{8} \mathrm{PFU} / \mathrm{mL}\right)$ on ice for $1-2 \mathrm{~h}$, before embedding in collagen gels. For in ovo viral infection, left wing buds of E3 (stage 17-19) chick embryos were injected with RCAS virus. The embryos were fixed at E10 for section in situ analysis.

\section{Explant harvesting and RT-PCR analysis}

Explants were lysed and processed for RNA analysis using either the method described previously (Munsterberg et al. 1995) or by means of a QIAGEN RNeasy minikit. PCRs were performed in MJ Research PCR machines. All the RT-PCR analyses were performed at least 2-15 times in independent experiments, with similar results obtained each time. Representatives of these analyses are shown. Because we found that various experimental regimens had a large effect on somitic cell proliferation and survival, we normalized all PCR analyses to an arbitrary level of GAPDH in each experiment by phosphoimager quantitation (BioRad, program: quality one). In addition, most PCR reactions were performed in the linear range and therefore are semiquantitative assessments of gene expression. The primers are GAPDH upper primer, 5'-AGTCATCCCTGAGCTGA ATG-3'; GAPDH lower primer, 5'-ACCATCAAGTCCACAA CACG-3'; Epiphycan upper primer, 5'-GCTGCCATCTACCT TGACT-3'; Epiphycan lower primer, 5'-CAAACGGGGCAGA CACAT-3'; Aggrecan upper primer, 5'-CCTGCCTGACCTC TTTGC-3'; Aggrecan lower primer, 5'-TGGGGAGGAGGGC AACAT-3'; Collagen IX upper primer, 5'-CAGGACTTATGA CAGGGAAC-3'; Collagen IX lower primer, 5'-TCTTGATT GTTGCTGGTAGG-3'; endogenous Nkx3.2 upper primer, 5'GGACCGTCTGTTGGTTTGT-3'; endogenous Nkx3.2 lower primer, 5'-CCCTACGGGACACGGTTAT-3'; viral Nkx3.2 upper primer, 5'-CAAGCATGGAAGCCGTCATT-3'; viral Nkx3.2 lower primer, 5'-GCGCTCCTCCTTCTTGTTGAGG-3'; viral Sox9 upper primer, 5'-CAAGCATGGAAGCCGTCATT-3'; viral Sox9 lower primer, $5^{\prime}$-GATGCACACGGGGAATTTGTC- 3 '; viral and endogenous Sox 9 upper primer, 5'-CTCCCCCAACGC- 
CATCTTCA-3'; viral and endogenous Sox9 lower primer, 5'AGCTGCTGATGCCGTAGGTA-3'; Paxl upper primer, 5'-GC TGGGTGGTGTCTTCGTGA-3'; Pax1 lower primer, 5' -GAATA CAAGCAGGGCGACCC-3'; Gli-1 upper primer, 5'-AAGCAT CAGAACCGCACCCACTC-3'; Gli-1 lower primer, 5'-CCAC CCGTGTTGCCCGTCATCTC-3'; Patched upper primer, 5'TCTTTTCCTGGGCTTACTTG-3'; Patched lower primer, 5'TTTTCCCAGTTTCCCAGTCA-3'; Ihh upper primer, 5'-GCT CATCCCGCTCGCCTACA-3'; Ihh lower primer, 5'-TCATC CCAGCCCTCCGTCAC-3'.

\section{BrdU labeling and TUNEL assay}

For BrdU labeling, explants were cultured for $7 \mathrm{~d}$. On the last day of culture, BrdU was added to the culture medium (10 $\mu \mathrm{M}$, Sigma) for $6 \mathrm{~h}$ prior to fixation with $4 \%$ PFA. The explants were incubated with $2 \mathrm{~N} \mathrm{HCl}$ and $0.1 \%$ Triton X-100 for $20 \mathrm{~min}$ and washed with $0.3 \mathrm{M}$ Tris- $\mathrm{HCl}(\mathrm{pH} 8.8) 0.15 \mathrm{M}$ Tris- $\mathrm{HCl}(\mathrm{pH} 8.8)$ and subsequently washed with PBS, $0.1 \%$ Triton X-100 (PBST). After incubating the explants in blocking buffer (PBS, 5\% goat serum, $1 \%$ horse serum, $0.1 \%$ Triton $\mathrm{X}-100$ ) for $45 \mathrm{~min}$, the explants were incubated with G3, the anti-BrdU antibody (1:200 dilution in blocking buffer, Developmental Studies Hybridoma Bank) at $4^{\circ} \mathrm{C}$ overnight. After four washes in PBST the next day, Cy3 goat-anti-mouse secondary antibody and Dapi were applied to the explants (1:250 for Cy3, 1:2000 for Dapi). After $1 \mathrm{~h}$ of incubation with the secondary antibody, the explants were washed with PBST four times. The explants were mounted with mounting media (Vector Lab) and viewed under a Zeiss fluorescence microscope. The percentage of BrdU-positive cells was averaged over five different fields.

For TUNEL staining, explants were treated with proteinase $\mathrm{K}$ $(20 \mu \mathrm{g} / \mathrm{mL}$ in PBS) before being fixed with $4 \%$ PFA. The explants were subsequently treated with $0.3 \% \mathrm{H}_{2} \mathrm{O}_{2}$ and $0.1 \% \mathrm{NaCi}$ trate, $0.1 \%$ Triton $\mathrm{X}-100$ before incubation with the TUNEL reaction mix. The entire assay was performed with a TUNEL staining kit (in situ cell death detection kit, POD, Roche) following the recommended procedure. The explants were mounted with mounting media from Vector lab. The percentage of TUNEL-positive cells was averaged over five different fields.

\section{Acknowledgments}

We thank Connie Cepko, William Gaffield, Richard Harland, Paul Sharp, and Cliff Tabin for the kind gift of either experimental reagents or constructs. We thank members of the Lassar lab for helpful discussions. This work was supported by NIH grants to A.B.L. Support for L.Z. was provided by a postdoctoral fellowship from the American Heart Association (9920213T) and a postdoctoral fellowship from the NIH (1F32AR48487-01). Support for H.K. was provided by a fellowship from l'Association pour la Recherche sur le Cancer and a long-term fellowship from the Human Frontier Science Program (LT00254/2000M). H.K. is also a recipient of a Foundation Bettencourt Schueller award. L.C.M. was supported by a National Defense Science and Engineering Graduate Fellowship from the Department of Defense.

The publication costs of this article were defrayed in part by payment of page charges. This article must therefore be hereby marked "advertisement" in accordance with 18 USC section 1734 solely to indicate this fact.

\section{References}

Akazawa, H., Komuro, I., Sugitani, Y., Yazaki, Y., Nagai, R., and Noda, T. 2000. Targeted disruption of the homeobox tran- scription factor bapxl results in lethal skeletal dysplasia with asplenia and gastroduodenal malformation. Genes Cells 5: 499-513.

Arnold, H.H. and Braun, T. 2000. Genetics of muscle determination and development. Curr. Top. Dev. Biol. 48: 129-164.

Bell, D.M., Leung, K.K., Wheatley, S.C., Ng, L.J., Zhou, S., Ling, K.W., Sham, M.H., Koopman, P., Tam, P.P., and Cheah, K.S. 1997. SOX9 directly regulates the type-II collagen gene. Nat. Genet. 16: 174-178.

Bi, W., Deng, J.M., Zhang, Z., Behringer, R.R., and de Crombrugghe, B. 1999. Sox9 is required for cartilage formation. Nat. Genet. 22: 85-89.

Borycki, A.G. and Emerson, Jr., C.P. 2000. Multiple tissue interactions and signal transduction pathways control somite myogenesis. Curr. Top. Dev. Biol. 48: 165-224.

Borycki, A.G., Brunk, B., Tajbakhsh, S., Buckingham, M., Chiang, C., and Emerson, Jr., C.P. 1999. Sonic hedgehog controls epaxial muscle determination through Myf5 activation. Development 126: 4053-4063.

Brand-Saberi, B., Ebensperger, C., Wilting, J., Balling, R., and Christ, B. 1993. The ventralizing effect of the notochord on somite differentiation in chick embryos. Anat. Embryol. (Berl.) 188: 239-245.

Britto, J.M., Tannahill, D., and Keynes, R.J. 2000. Life, death and Sonic hedgehog. Bioessays 22: 499-502.

Chiang, C., Litingtung, Y., Lee, E., Young, K.E., Corden, J.L., Westphal, H., and Beachy, P.A. 1996. Cyclopia and defective axial patterning in mice lacking Sonic hedgehog gene function. Nature 383: 407-413.

Cooper, M.K., Porter, J.A., Young, K.E., and Beachy, P.A. 1998. Teratogen-mediated inhibition of target tissue response to Shh signaling. Science 280: 1603-1607.

Deutsch, U., Dressler, G.R., and Gruss, P. 1988. Pax 1, a member of a paired box homologous murine gene family, is expressed in segmented structures during development. Cell 53: 617-625.

Dietrich, S., Schubert, F.R., and Gruss, P. 1993. Altered Pax gene expression in murine notochord mutants: The notochord is required to initiate and maintain ventral identity in the somite. Mech. Dev. 44: 189-207.

Dockter, J.L. 2000. Sclerotome induction and differentiation. Curr. Top. Dev. Biol. 48: 77-127.

Dyer, M.A., Farrington, S.M., Mohn, D., Munday, J.R., and Baron, M.H. 2001. Indian hedgehog activates hematopoiesis and vasculogenesis and can respecify prospective neurectodermal cell fate in the mouse embryo. Development 128: $1717-1730$

Fan, C.M. and Tessier-Lavigne, M. 1994. Patterning of mammalian somites by surface ectoderm and notochord: Evidence for sclerotome induction by a hedgehog homolog. Cell 79: $1175-1186$.

Furumoto, T.A., Miura, N., Akasaka, T., Mizutani-Koseki, Y., Sudo, H., Fukuda, K., Maekawa, M., Yuasa, S., Fu, Y., Moriya, H., et al. 1999. Notochord-dependent expression of MFH1 and PAX1 cooperates to maintain the proliferation of sclerotome cells during the vertebral column development. Dev. Biol. 210: 15-29.

Glumoff, V., Savontaus, M., Vehanen, J., and Vuorio, E. 1994. Analysis of aggrecan and tenascin gene expression in mouse skeletal tissues by northern and in situ hybridization using species specific cDNA probes. Biochim. Biophys. Acta 1219: 613-622.

Healy, C., Uwanogho, D., and Sharpe, P.T. 1999. Regulation and role of Sox9 in cartilage formation. Dev. Dyn. 215: 69-78.

Hirsinger, E., Jouve, C., Dubrulle, J., and Pourquie, O. 2000 Somite formation and patterning. Int. Rev. Cytol. 198: 1-65. 
Inada, M., Yasui, T., Nomura, S., Miyake, S., Deguchi, K., Himeno, M., Sato, M., Yamagiwa, H., Kimura, T., Yasui, N., et al. 1999. Maturational disturbance of chondrocytes in Cbfa1deficient mice. Dev. Dyn. 214: 279-290.

Incardona, J.P., Gaffield, W., Lange, Y., Cooney, A., Pentchev, P.G., Liu, S., Watson, J.A., Kapur, R.P., and Roelink, H. 2000. Cyclopamine inhibition of Sonic hedgehog signal transduction is not mediated through effects on cholesterol transport. Dev. Biol. 224: 440-452.

Iwasaki, M., Le, A.X., and Helms, J.A. 1997. Expression of Indian hedgehog, bone morphogenetic protein 6 and gli during skeletal morphogenesis. Mech. Dev. 69: 197-202.

Johnson, J., Shinomura, T., Eberspaecher, H., Pinero, G., Decrombrugghe, B., and Hook, M. 1999. Expression and localization of PG-Lb/epiphycan during mouse development. Dev. Dyn. 216: 499-510.

Johnson, R.L., Laufer, E., Riddle, R.D., and Tabin, C. 1994. Ectopic expression of Sonic hedgehog alters dorsal-ventral patterning of somites. Cell 79: 1165-1173.

Karp, S.J., Schipani, E., St-Jacques, B., Hunzelman, J., Kronenberg, H., and McMahon, A.P. 2000. Indian hedgehog coordinates endochondral bone growth and morphogenesis via parathyroid hormone related-protein-dependent and -independent pathways. Development 127: 543-548.

Kawakami, Y., Ishikawa, T., Shimabara, M., Tanda, N., Enomoto-Iwamoto, M., Iwamoto, M., Kuwana, T., Ueki, A., Noji, S., and Nohno, T. 1996. BMP signaling during bone pattern determination in the developing limb. Development 122: $3557-3566$

Kim, I.S., Otto, F., Zabel, B., and Mundlos, S. 1999. Regulation of chondrocyte differentiation by Cbfa1. Mech. Dev. 80: $159-170$.

Kim, S.K. and Melton, D.A. 1998. Pancreas development is promoted by cyclopamine, a hedgehog signaling inhibitor. Proc. Natl. Acad. Sci. 95: 13036-13041.

Komori, T., Yagi, H., Nomura, S., Yamaguchi, A., Sasaki, K., Deguchi, K., Shimizu, Y., Bronson, R.T., Gao, Y.H., Inada, M., et al. 1997. Targeted disruption of Cbfal results in a complete lack of bone formation owing to maturational arrest of osteoblasts. Cell 89: 755-764.

Lefebvre, V., Huang, W., Harley, V.R., Goodfellow, P.N., and de Crombrugghe, B. 1997. SOX9 is a potent activator of the chondrocyte-specific enhancer of the pro alpha1(II) collagen gene. Mol. Cell. Biol. 17: 2336-2346.

Lefebvre, V., Li, P., and de Crombrugghe, B. 1998. A new long form of Sox5 (L-Sox5), Sox6 and Sox9 are coexpressed in chondrogenesis and cooperatively activate the type II collagen gene. EMBO J. 17: 5718-5733.

Lettice, L.A., Purdie, L.A., Carlson, G.J., Kilanowski, F., Dorin, J., and Hill, R.E. 1999. The mouse bagpipe gene controls development of axial skeleton, skull, and spleen. Proc. Natl. Acad. Sci. 96: 9695-9700.

Long, F., Zhang, X.M., Karp, S., Yang, Y., and McMahon, A.P. 2001. Genetic manipulation of hedgehog signaling in the endochondral skeleton reveals a direct role in the regulation of chondrocyte proliferation. Development 128: 5099-5108.

Marcelle, C., Ahlgren, S., and Bronner-Fraser, M. 1999. In vivo regulation of somite differentiation and proliferation by Sonic Hedgehog. Dev. Biol. 214: 277-287.

Marigo, V., Scott, M.P., Johnson, R.L., Goodrich, L.V., and Tabin, C.J. 1996. Conservation in hedgehog signaling: Induction of a chicken patched homolog by Sonic hedgehog in the developing limb. Development 122: 1225-1233.

Marvin, M.J., Di Rocco, G., Gardiner, A., Bush, S.M., and Lassar, A.B. 2001. Inhibition of Wnt activity induces heart formation from posterior mesoderm. Genes \& Dev. 15: 316-327.
Minina, E., Wenzel, H.M., Kreschel, C., Karp, S., Gaffield, W. McMahon, A.P., and Vortkamp, A. 2001. BMP and Ihh/ PTHrP signaling interact to coordinate chondrocyte proliferation and differentiation. Development 128: 4523-4534.

Munsterberg, A.E., Kitajewski, J., Bumcrot, D.A., McMahon, A.P., and Lassar, A.B. 1995. Combinatorial signaling by Sonic hedgehog and Wnt family members induces myogenic bHLH gene expression in the somite. Genes \& Dev. 9: 29112922.

Murtaugh, L.C., Chyung, J.H., and Lassar, A.B. 1999. Sonic hedgehog promotes somitic chondrogenesis by altering the cellular response to BMP signaling. Genes \& Dev. 13: 225237.

Murtaugh, L.C., Zeng, L., Chyung, J.H., and Lassar, A.B. 2001. The chick transcriptional repressor $\mathrm{Nkx} 3.2$ acts downstream of Shh to promote BMP-dependent axial chondrogenesis. Dev. Cell 1: 411-422.

Neubuser, A., Koseki, H., and Balling, R. 1995. Characterization and developmental expression of Pax9, a paired-box-containing gene related to Paxl. Dev. Biol. 170: 701-716.

$\mathrm{Ng}$, L.J., Wheatley, S., Muscat, G.E., Conway-Campbell, J., Bowles, J., Wright, E., Bell, D.M., Tam, P.P., Cheah, K.S., and Koopman, P. 1997. SOX9 binds DNA, activates transcription, and coexpresses with type II collagen during chondrogenesis in the mouse. Dev. Biol. 183: 108-121.

Pathi, S., Rutenberg, J.B., Johnson, R.L., and Vortkamp, A. 1999. Interaction of Ihh and BMP/Noggin signaling during cartilage differentiation. Dev. Biol. 209: 239-253.

Peters, H., Wilm, B., Sakai, N., Imai, K., Maas, R., and Balling, R. 1999. Paxl and Pax9 synergistically regulate vertebral column development. Development 126: 5399-5408.

Platt, K.A., Michaud, J., and Joyner, A.L. 1997. Expression of the mouse Gli and Ptc genes is adjacent to embryonic sources of hedgehog signals suggesting a conservation of pathways between flies and mice. Mech. Dev. 62: 121-135.

Pourquie, O., Coltey, M., Teillet, M.A., Ordahl, C., and Le Douarin, N.M. 1993. Control of dorsoventral patterning of somitic derivatives by notochord and floor plate. Proc. Nat1. Acad. Sci. 90: 5242-5246.

Reshef, R., Maroto, M., and Lassar, A.B. 1998. Regulation of dorsal somitic cell fates: BMPs and Noggin control the timing and pattern of myogenic regulator expression. Genes \& Dev. 12: 290-303.

Schoenwolf, G.C., Garcia-Martinez, V., and Dias, M.S. 1992. Mesoderm movement and fate during avian gastrulation and neurulation. Dev. Dyn. 193: 235-248.

Sekiya, I., Tsuji, K., Koopman, P., Watanabe, H., Yamada, Y., Shinomiya, K., Nifuji, A., and Noda, M. 2000. SOX9 enhances aggrecan gene promoter/enhancer activity and is upregulated by retinoic acid in a cartilage-derived cell line, TC6. J. Biol. Chem. 275: 10738-10744.

Smits, P., Li, P., Mandel, J., Zhang, Z., Deng, J.M., Behringer, R., de Crombrugghe, B., and Lefebvre, V. 2001. The transcription factors L-Sox5 and Sox6 are essential for cartilage formation. Dev. Cell 1: 277-290.

St-Jacques, B., Hammerschmidt, M., and McMahon, A.P. 1999. Indian hedgehog signaling regulates proliferation and differentiation of chondrocytes and is essential for bone formation. Genes \& Dev. 13: 2072-2086.

Stockdale, F.E., Nikovits, Jr., W. and Christ, B. 2000. Molecular and cellular biology of avian somite development. Dev. Dyn. 219: 304-321.

Takeda, S., Bonnamy, J.P., Owen, M.J., Ducy, P., and Karsenty, G. 2001. Continuous expression of Cbfal in nonhypertrophic chondrocytes uncovers its ability to induce hypertrophic chondrocyte differentiation and partially rescues Cbfa1- 
deficient mice. Genes \& Dev. 15: 467-481.

Teillet, M., Watanabe, Y., Jeffs, P., Duprez, D., Lapointe, F., and Le Douarin, N.M. 1998. Sonic hedgehog is required for survival of both myogenic and chondrogenic somitic lineages. Development 125: 2019-2030.

Tonegawa, A., Funayama, N., Ueno, N., and Takahashi, Y. 1997. Mesodermal subdivision along the mediolateral axis in chicken controlled by different concentrations of BMP-4. Development 124: 1975-1984.

Tribioli, C. and Lufkin, T. 1999. The murine Bapx1 homeobox gene plays a critical role in embryonic development of the axial skeleton and spleen. Development 126: 5699-5711.

Tribioli, C., Frasch, M., and Lufkin, T. 1997. Bapx1: An evolutionary conserved homologue of the Drosophila bagpipe homeobox gene is expressed in splanchnic mesoderm and the embryonic skeleton. Mech. Dev. 65: 145-162.

Ueta, C., Iwamoto, M., Kanatani, N., Yoshida, C., Liu, Y., Enomoto-Iwamoto, M., Ohmori, T., Enomoto, H., Nakata, K., Takada, K., et al. 2001. Skeletal malformations caused by overexpression of Cbfal or its dominant negative form in chondrocytes. J. Cell Biol. 153: 87-100.

Vortkamp, A., Lee, K., Lanske, B., Segre, G.V., Kronenberg, H.M., and Tabin, C.J. 1996. Regulation of rate of cartilage differentiation by Indian hedgehog and PTH-related protein. Science 273: 613-622.

Wilm, B., Dahl, E., Peters, H., Balling, R., and Imai, K. 1998. Targeted disruption of Paxl defines its null phenotype and proves haploinsufficiency. Proc. Natl. Acad. Sci. 95: 86928697.

Winnier, G.E., Hargett, L., and Hogan, B.L. 1997. The winged helix transcription factor MFH1 is required for proliferation and patterning of paraxial mesoderm in the mouse embryo. Genes \& Dev. 11: 926-940.

Zhou, G., Lefebvre, V., Zhang, Z., Eberspaecher, H., and de Crombrugghe, B. 1998. Three high mobility group-like sequences within a 48-base pair enhancer of the Col2al gene are required for cartilage-specific expression in vivo. J. Biol. Chem. 273: 14989-14997.

Zou, H., Wieser, R., Massague, J., and Niswander, L. 1997. Distinct roles of type I bone morphogenetic protein receptors in the formation and differentiation of cartilage. Genes \& Dev. 11: 2191-2203. 


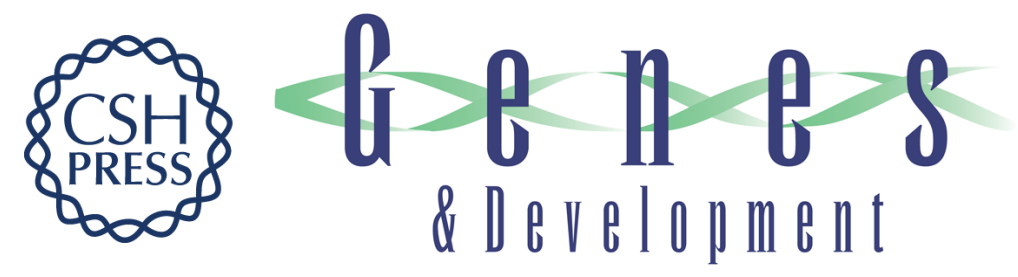

\title{
Shh establishes an Nkx3.2/Sox9 autoregulatory loop that is maintained by BMP signals to induce somitic chondrogenesis
}

\author{
Li Zeng, Hervé Kempf, L. Charles Murtaugh, et al.
}

Genes Dev. 2002, 16:

Access the most recent version at doi:10.1101/gad.1008002

References This article cites 63 articles, 30 of which can be accessed free at:

http://genesdev.cshlp.org/content/16/15/1990.full.html\#ref-list-1

License

Email Alerting Receive free email alerts when new articles cite this article - sign up in the box at the top Service right corner of the article or click here.

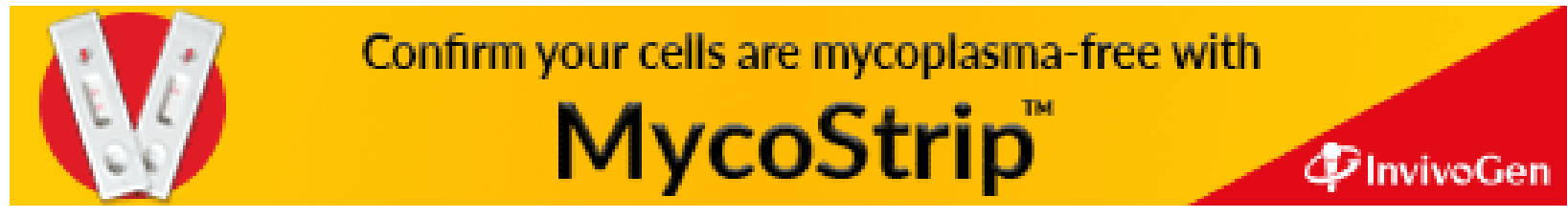

